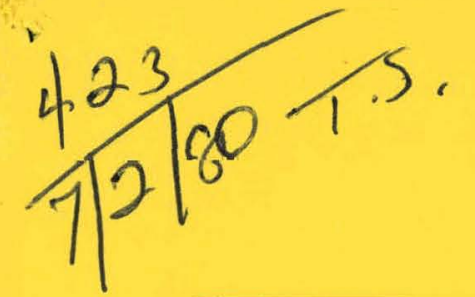

\title{
MSSTER
}

\section{LOCALIZED CORROSION OF ALUMINUM ALLOYS FOR OTEC HEAT EXCHANGERS}

Stephen C. Dexter

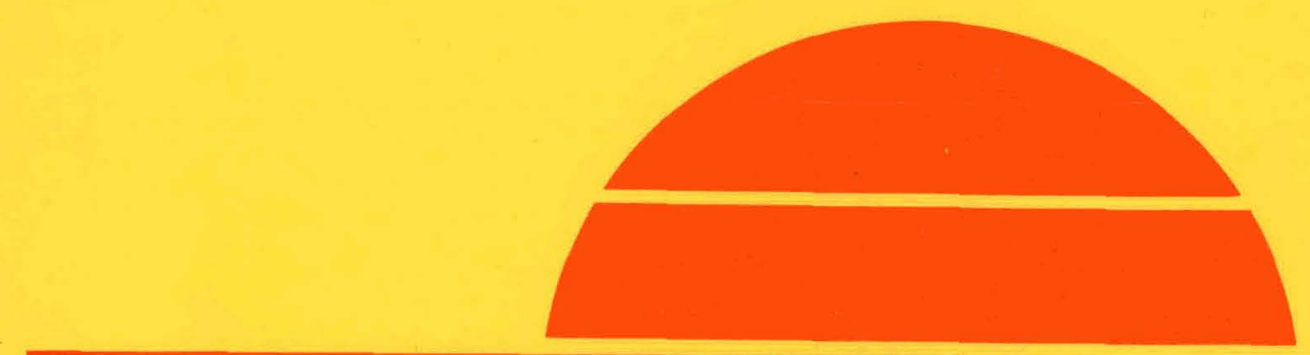

Argonne National Laboratory 9700 South Cass Avenue Argonne, Illinois 60439

Prepared for the

U. S. Department of Energy

Division of Central Solar Technology under Contract W-31-109-Eng-38 


\section{DISCLAIMER}

This report was prepared as an account of work sponsored by an agency of the United States Government. Neither the United States Government nor any agency Thereof, nor any of their employees, makes any warranty, express or implied, or assumes any legal liability or responsibility for the accuracy, completeness, or usefulness of any information, apparatus, product, or process disclosed, or represents that its use would not infringe privately owned rights. Reference herein to any specific commercial product, process, or service by trade name, trademark, manufacturer, or otherwise does not necessarily constitute or imply its endorsement, recommendation, or favoring by the United States Government or any agency thereof. The views and opinions of authors expressed herein do not necessarily state or reflect those of the United States Government or any agency thereof. 


\section{DISCLAIMER}

Portions of this document may be illegible in electronic image products. Images are produced from the best available original document. 
The facilities of Argonne National Laboratory are owned by the United States Government. Under the terms of a contract (W-31-109-Eng-38) among the U. S. Department of Energy, Argonne Universities Association and The University of Chicago, the University employs the staff and operates the Laboratory in accordance with policies and programs formulated, approved and reviewed by the Association.

\section{MEMBERS OF ARGONNE UNIVERSITIES ASSOCIATION}

The University of Arizona

Carnegie-Mellon University

Case Western Reserve University

The University of Chicago

University of Cincinnati

Illinois Institute of Technology

University of Illinois

Indiana Inniversity

The University of Iowa

Iowa State University
The University of Kansas

Kansas State University

Loyola University of Chicago

Marquette University

The University of Michigan

Michigan State University

University of Minnesota

University of Missouri

Northwestern University

University of Notre Dame
The Ohio State University

Ohio University

The Pennsylvania State University

Purdue University

Saint Louis University

Southern Illinois University

The University of Texas at Austin

Washington University

Wayne State University

The University of Wisconsin-Madison

\section{NOTICE}

This report was prepared as an account of work sponsored by an agency of the United States Government. Neither the United States Government or any agency thereof, nor any of their employees, make any warranty, express or implied, or assume any legal liability or responsibility for the accuracy, completeness, or usefulness of any information, apparatus, product, or process disclosed, or represent that its use would not infringe privately owned rights. Reference herein to any specific commercial product, process, or service by trade name, mark, manufacturer, or otherwise, does not necessarily constitute or imply its endorsement, recommendation, or favoring by the United States Government or any agency thereof. The views and opinions of authors expressed herein do not necessarily state or reflect those of the United States Government or any agency thereof.

Printed in the United States of America

Available from

National Technical Information Service

U. S. Department of Commerce

5285 Port Royal Road

Springfield, VA 22161

NTIS price codes

Printed copy: A04

Microfiche copy: A01 
ARGONNE NATIONAL LABORATORY.

9700 South Cass Avenue

Argonne, Illinois 60439

\section{LOCALIZED CORROSION OF ALUMINUM ALLOYS FOR OTEC . HEAT EXCHANGERS}

Stephen C. Dexter

University of Delaware

College of Marine Studies

Lewes, Delaware 19958

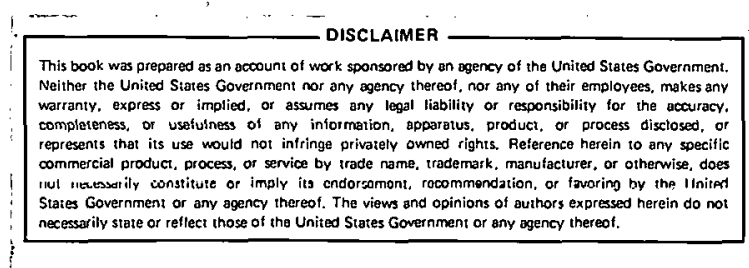

Prepared for the

U. 3. Department of Energy under Contract EY-76-S-02-2957 


\section{THIS PAGE}

\section{WAS INTENTIONALILY}

LEFT BLANK 


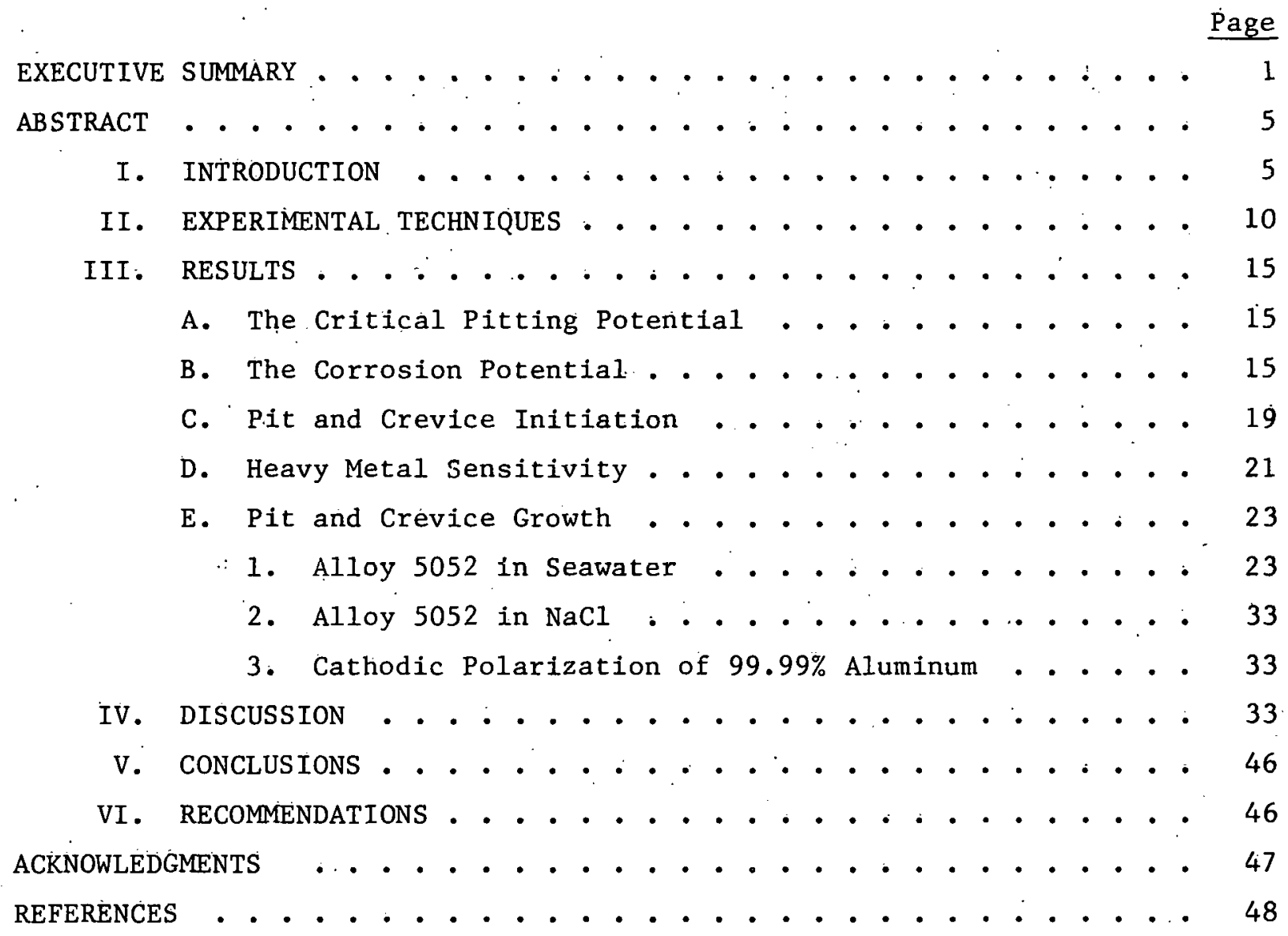




\section{LIST OF FIGURES}

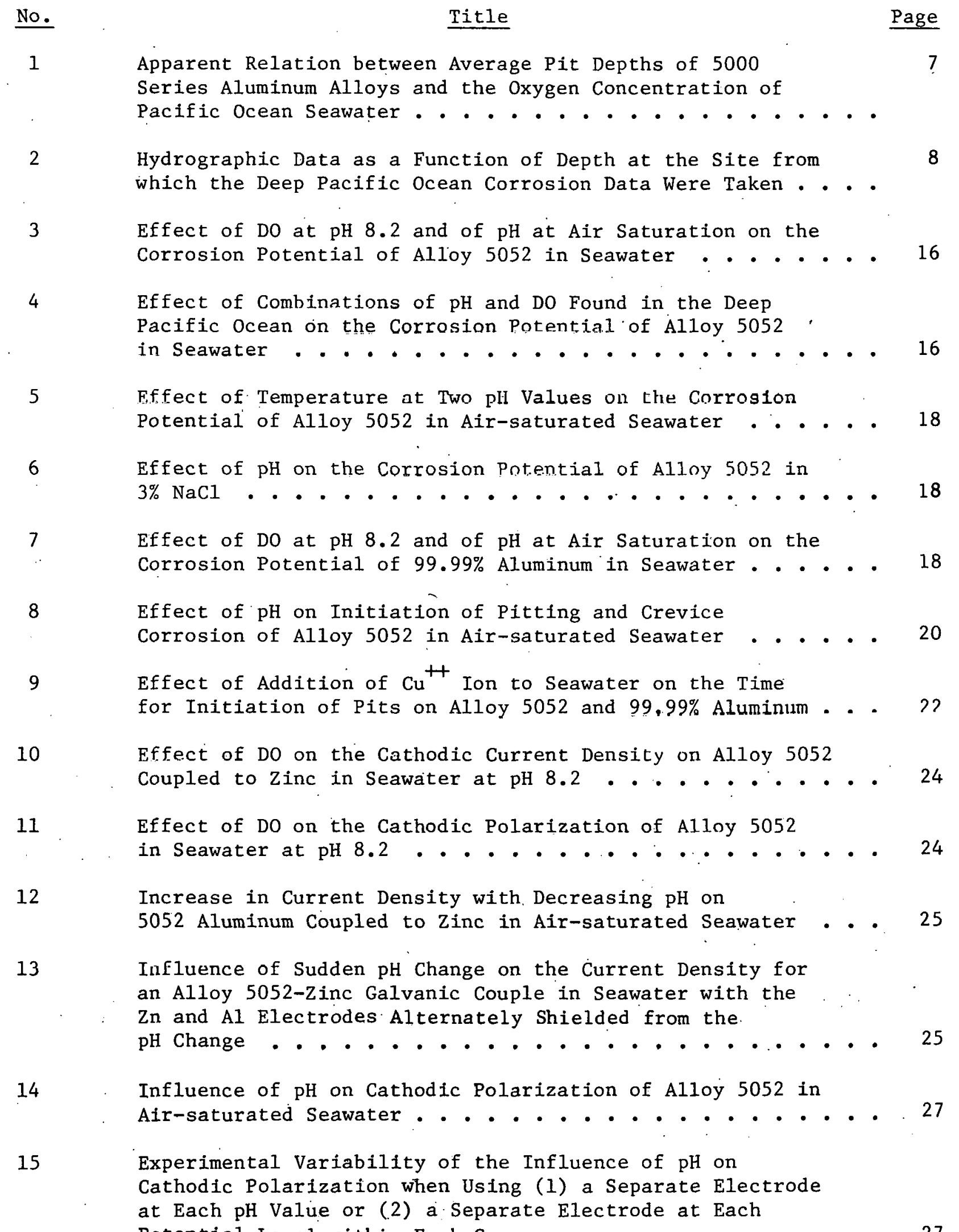

Potential Level within Each Curve . . . . . . . . . 
16. : Comparison of Cathodic Polarization Data in Air-saturated Seawater at $\mathrm{pH} 7.2$ as Controlled by $\mathrm{HCl}$ Additions and by $\mathrm{CO}_{2}$ Partial Pressure : : . . . . . . . . . . . . . .

Effect of $\mathrm{pH}$ on Cathodic Polarization of Alloy 5052 in

Seawater with $3 \mathrm{ppm}$ DO at $23 \pm 2{ }^{\circ} \mathrm{C}: . . . . \ldots . . .$.

Effect of $\mathrm{pH}$ on "Cathodic Polarization of Alloy 5052 in

Seawater with $7.2 \mathrm{ppm}$ DO at $4.0^{\circ} \mathrm{C} \ldots . . . . .$.

Effect of $\mathrm{pH}$ on Cathodic Polarization of Alloy 5052 in

Seawater with $5.0 \mathrm{ppm}$ DO at $15^{\circ} \mathrm{C}$...........

Effect of $\mathrm{pH}$ on Cathodic Polarization of Alloy 5052 in

Seawater with $0.6 \mathrm{ppm}$ DO at $4.0^{\circ} \mathrm{C}$. . . . . . . .

Cathodic Polarization of Alloy 5052 in Seawater at

Combinations of $\mathrm{pH}, \mathrm{DO}$ and Temperature in the Deep Ocean . .

Cathodic Polarization of Alloy 5052 in Air-saturated $3 \% \mathrm{NaCl}$ at $23 \pm 2{ }^{\circ} \mathrm{C}$

Effect of DO on Cathodic Polarization of $99.99 \%$ Aluminum in Seawater at $\mathrm{pH} 8.2$

Influence of $\mathrm{pH}$ on Cathodic Polarization of $99.99 \%$

Aluminum in Air-saturated Seawater ...........

Corrosion Weight-loss Data for Alloy 5052 in Halifax

Seawater .........................

Pit-density Data Reported by Reinhart for Aluminum Alloys at the Pacific Ocean Test Site Plotted as a Function of

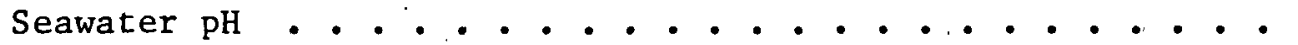




\section{LIST OF TABLES}

No.

Title

Page

Composition of Alloys Used . . . . . . . . . . . . 12

Approximate Ocean Depth Ranges Corresponding to Experimenta1

Combinations of $\mathrm{pH}$ and Dissolved Oxygen . . . . . . . 16

III Summary of Polarization Data for Alloy 5052 . . . . . . . 32

IV Wall Thickness of Tubing Required for Various Lifetimes

and Pit Densities . . . . . . . . . . . . . . . 40 


\title{
LOCALIZED CORROSION OF ALUMINUM ALLOYS \\ FOR OTEC HEAT EXCHANGERS
}

\author{
Stephen C. Dexter \\ University of Delaware \\ College of Marine Studies \\ Lewes, Delaware 19958

\section{EXECUTIVE SUMMARY}

Aluminum-magnesium alloy 5052 is one of the leading candidates for OTEC heat exchanger and condenser tubing. Existing field data show that alloy 5052 corrodes by pitting and crevice corrosion in seawater. These same data suggest that corrosion rates may be accelerated in certain deep Pacific Ocean waters similar to those that will be utilized in OTEC condensers.

This paper reports the results of a laboratory study undertaken to assess (1) whether accelerated corrosion of aluminum alloy 5052 in the deep ocean is a real possibility, (2) whether accelerated deep ocean corrosion will be of concern to an OTEC plant using aluminum alloy heat exchanger tubing, and (3) what deep ocean variables could be responsible for an increased corrosion rate. Accordingly, the corrosion behavior of both alloy 5052 and pure aluminum (which serves as a baseline material) has been measured in the laboratory under simulated deep ocean conditions. The effects of dissolved oxygen, $\mathrm{pH}$, temperature and copper ion concentration of the seawater have been studied by both simple immersion and galvanic cell tests under controlled conditions and by electrochemical techniques.

Through this program, objectives (1) and (3) above have been completed. Objective (2) has been partially completed and the work necessary to finish it has been outlined and recommended. It is shown that a decrease in $\mathrm{pH}$ from 8.2 to 7.5 as found in the deep ocean both decreases the time for pits to initiate and increases their growth rate. A decrease in dissolved oxygen has the opposite effect, but when $\mathrm{pH}$ and dissolved oxygen are varied together as in the deep ocean, the $\mathrm{pH}$ effect predominates. The effects of a decrease in temperature with depth are to encourage rapid pit initiation and to slow down the pit growth rate. From the data in which oxygen, $\mathrm{pH}$ and temperature are all varied together, it is concluded that an increase in corrosion rate is indeed to be expected in many deep ocean waters, and that a combination of low $\mathrm{pH}$ and low temperature is responsible, rather than low oxygen as many had previously belifeved. The most corrosive set of conditions 
encountered was low $\mathrm{pH}$ and temperature coupled with high oxygen. Fortunately for OTEC, such conditions are not found occurring together naturally in the ocean. The most corrosive set of real conditions was found to be in the midrange of all three variables where temperature and $\mathrm{pH}$ are low enough to give rapid corrosion initiation, and the dissolved oxygen is high enough to permit high growth rates. Such conditions are found at depths of 150 to 400 meters in the Pacific Ocean, while in the Atlantic they may be found at greater depths due to the higher overall levels of oxygen. For this reason, it is recommended that oxygen, $\mathrm{pH}$ and temperature profiles be measured at all potential OTEC sites before detailed design of a plant to be located at. that site is begun. Using the hydrographic data along with the polarization techniques described in this report, the depths corresponding to the most corrosive conditions at that site can be identified, and the plant designed to avoid locating the cold and warm water intakes at these depths. For most locations it should be possible, using the techniques we have developed, to locate the warm water intake above and the cold water intake below the most corrosive depth.

It should be noted that although the most highly corrosive set of conditions identified by our experimental program do not occur together naturally, it may be possible to create them artificially inside an OTEC condenser taking in deep water having low $\mathrm{pH}$, low temperature and low Do. The velocity of the water through the tubing may increase the tranoport of oxygen to the surface sufficiently to raise the effective Do and make the water very corrosive compared to surface water, especially if pits have already initiated during a prior shutdown period. A laboratory program to assess the danger of this possibility has been proposed, but not yet been funded.

It is shown that pit initiation times for alloy 5052, especially under quiescent low $\mathrm{pH}$ conditions, can be as short as half a day. This means that some pitting is almost inevitable during shutdown periods, and especially during the initial start-up period before corrosion product films have had a chance to build up. In this connection, it is recommended that heat exchangers be designed to avoid zero velocity conditions and to provide for complete drainage of the tubing during maintenance periods longer than onehalf day. Due to the possibility of short initiation times, it is also recommended that OTEC consider either attempting to avoid pitting altogether 
by a combination of cladding and maintenance of a continuous flow, or controlling the perforation of unclad tubing by inducing as high a pit density as possible and selecting the proper tube wall thickness. A methodology is outlined for combining existing corrosion data, laboratory electrochemical data such as given in this report and a knowledge of the number of pits on the surface, to predict corrosion rates at an OTEC site for which the proper hydrographic data have been measured, but for which there are no corrosion data. A design engineer would then use this information to choose the proper tube wall thickness to obtain the desired lifetime. Data on the effects of $\mathrm{Cu}^{++}$ions on both alloy 5052 and $99.99 \%$ aluminum are presented which show that $\mathrm{Cu}^{+4}$ concentrations as $10 \mathrm{w}$ as $30 \mathrm{ppb}$ may accelerate corrosion. Therefore, it is recommended that copper-nickel components upstream of aluminum alloy heat exchanger tubing be avoided if at all possible. In case it is decided that copper-nickel intake screening is necessary, an experimental program to determine the severity of the problem is suggested.

A final recommendation based on our results is that all proposed chemical cleaning techniques be examined carefully to see if they could lead to even a temporary (i.e., one-half hour or longer) combination of low $\mathrm{pH}$ and high DO on the seawater side of the tubing. Any cleaning procedure that has this potential should be rejected if aluminum tubing is chosen, as such conditions could lead to severe corrosion. 
THIS PAGE

\section{WAS INTENTIONALLY LEFT BLANK}




\title{
LOCALIZED CORROSION OF ALUMINUM ALLOYS \\ FOR OTEC HEAT EXCHANGERS
}

\author{
Stephen C. Dexter \\ University of Delaware \\ College of Marine Studies \\ Lewes, Delaware 19958
}

The effects of dissolved oxygen, $\mathrm{pH}$ and temperature on the rate of initiation and growth of pitting and crevice corrosion of aluminum alloy 5052 and pure aluminum have been determined. Variations in $\mathrm{pH}$ and temperature rather than dissolved oxygen are shown to account for increased corrosion rates of 5000 series aluminum alloys that have been reported for deep ocean exposures. The impact of these results on. the use of aluminum for OTEC heat exchanger tubing and on possible approaches to corrosion control are discussed.

\section{T. TNTRODUCTION}

The long-term effectiveness of any Ocean Thermal Energy Conversion (OTEC) type power-generating plant depends critically on the performance of the material selected as heat exchanger tubing for the evaporator and condenser. ${ }^{1}$ Several aluminum alloys are prime candidates for this application due to the high strength-to-weight ratio, resistance to general corrosion and high thermal conductivity. ${ }^{2}$ Alloy 5052, a weldable, nonheat treatable aluminummagnesium alloy, which is readily available in seamless tubing, has particularly been recommended for this service. ${ }^{3}$

The corrosion behavior of aluminum alloy 5052 in surface seawater ${ }^{2-14}$ and in desalination environments ${ }^{15,16}$ has been studied and is reasonably we11 characterized. Less is known about its behavior in deep ocean waters ${ }^{17-19}$ typical of those to which an OTEC installation will be subjected. The desalination data are encouraging because, although rapid initial corrosion rates were observed, the rate of penetration by pitting slowed with time and tended to become self-limiting. 16 Caution should be exercised, however, when attempting to apply the desalination data to OTEC because the environments are different. The desalination environment typically involves temperatures from 65 to $120^{\circ} \mathrm{C}$; dissolved oxygen concentrations below $0.1 \mathrm{ppm}$, $\mathrm{pH}$ in the acidic range from 4 to 7.6 and higher than ambient salinity.16 
In contrast, the OTEC environment involves temperatures from 4 to $40^{\circ} \mathrm{C}$, dissolved oxygen from 0.5 to $7.5 \mathrm{ppm}$, pH from 7.4 to 8.4 and ambient salinity.

The corrosion data that are available for 5000 series aluminum alloys at various depths in the Pacific Ocean show that these alloys may suffer accelerated rates of corrosion in the deep ocean when compared with those at the surface. ${ }^{8,19}$ The rates that were reported reached a maximum of three times those of the surface at a depth of 500 to 900 meters, then decreased again to twice the surface rate at 2000 meters. This is shown averaged over all alloys tested in Figure 1. This is of concern to the OTEC Program because the cold water inlet pipe of proposed OTEC plants may be taking in deep ocean water similar to that in which the above maximum corrosion rates were reported. Figure 2 shows the variation with depth of dissolved oxygen, $\mathrm{pH}$, temperature and salinity at the sites from which the deep Pacific Ocean corrosion data were obtained. 19 Note that the dissolved oxygen concentration reaches a minimum at the same 500 to 900 -meter depth at which the maximum corrosion rate was reported. For this reason, it has usually been assumed that the low dissolved oxygen concentration was in some way responsible for the increased corrosion rate. ${ }^{8,19}$ The objectives of the research program, the results of which are given in this report, were to assess what threat, if any, an increase in corrosion rate of 5000 series aluminum alloys in the deep ocean may pose to the use of aluminum alloy heat exchanger tubing in OTEC installations and to determine whether or not decreased oxygen is the causal agent for the increased rate.

Other factors could also be important in determining the rate. For instance, the $\mathrm{pH}$ curve of Figure 2 has the same shape as that of the dissolved oxygen curve, and other data from the Pacific Ocean have shown 20 that the inorganic substances $\mathrm{NO}_{3}{ }^{-} \mathrm{SiO}_{3}-$ and $\mathrm{PO}_{4}{ }^{3-}$. often reach maximum concentrations at the same 500 to 900-meter depth. Morenver, many of the individual 5000 series alloys behave quite differently ${ }^{21}$ from the average shown in Figure 1. It is known ${ }^{9,22}$ that aluminum and aluminum alloys suffer accelerated rates of attack at $\mathrm{pH}$ values above 10 and below 4, but no detailed data have been reported on the effects of $\mathrm{pH}$ within the normal range. (7.4 to 8.2) of open ocean seawater. It has been reported ${ }^{16}$ that several aluminum alloys, including 5052, show little effect of dissolved oxygen in the range from 30 to $1000 \mathrm{ppb}$, while the same alloys are sensitive to $\mathrm{pH}$ changes between 3.8 and 7.4 . In addition, aluminum and aluminum alloys, because of their active nature, 


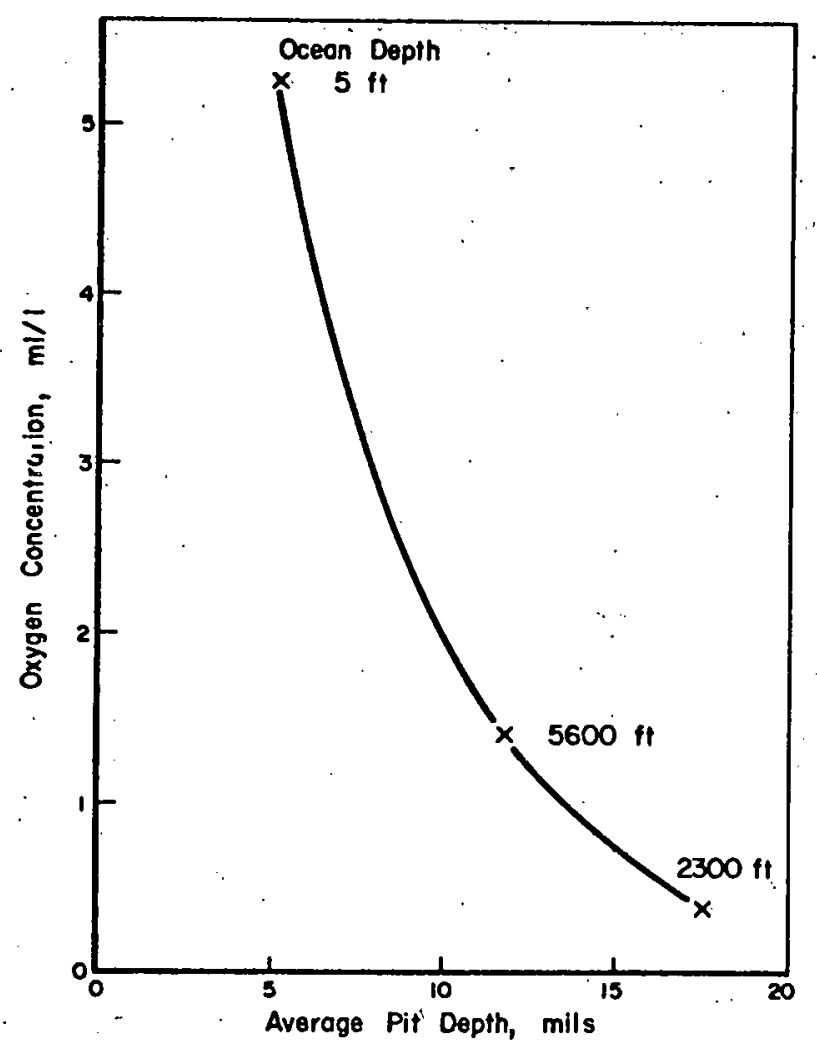

Figure 1. Apparent Relation between Average Pit Depths of $5000^{\circ}$ Series Aluminum Alloys and the Oxygen Concentration of Pacific Ocean Seawater ${ }^{8}$ 


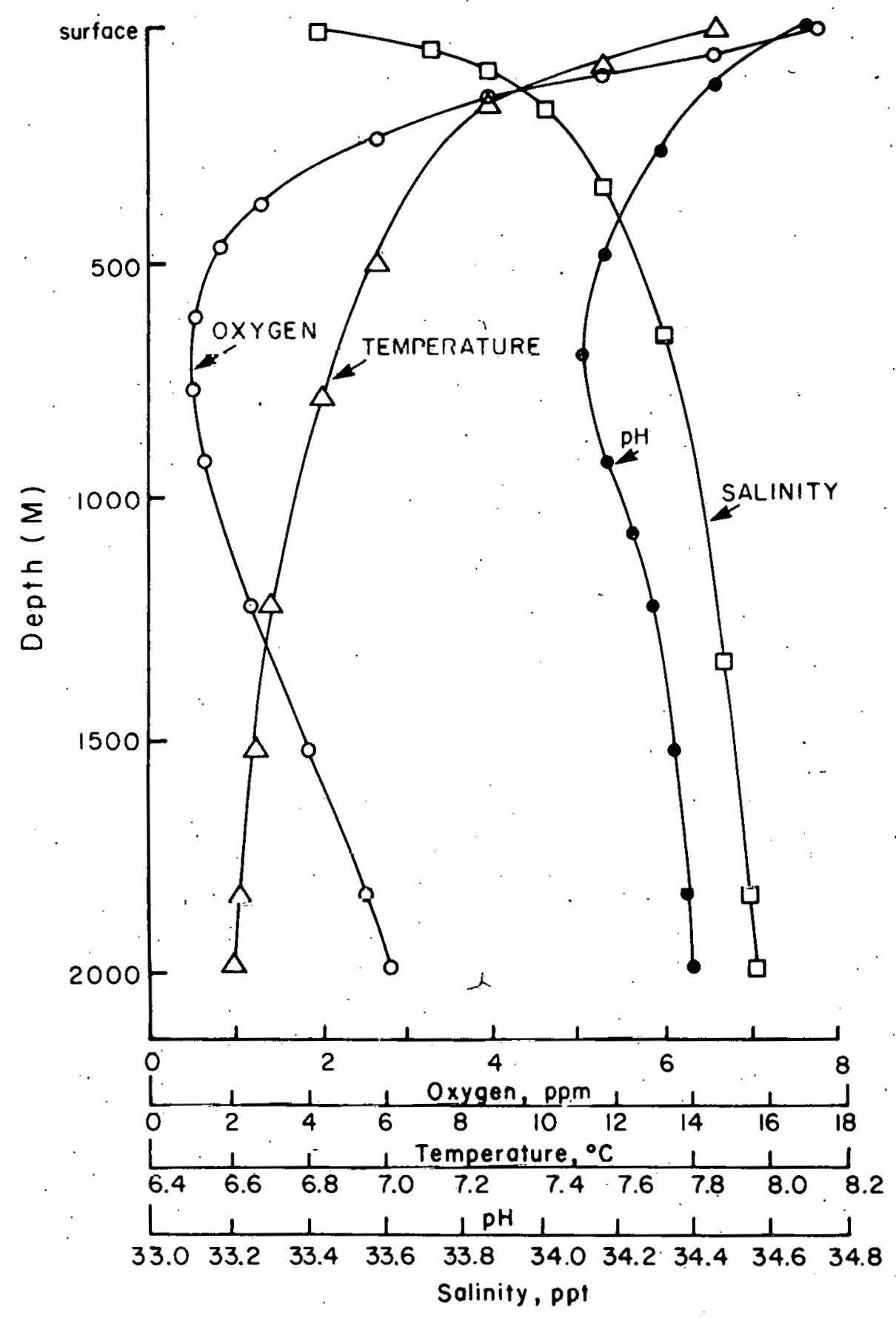

Figure 2. Hydrographic Data as a Function of Depth at the Site from which the Deep Pacific Ocean Corrosion Data Were. Taken 19 
are known to scavenge heavy metals from aqueous solutions.23-25 Cupric ions in particular can cause pitting of aluminum alloys in freshwater if present in concentrations exceeding about $0.1 \mathrm{ppm} .{ }^{23,24}$ Since OTEC plants may be using copper-nickel intake screening upstream of the evaporator and perhaps the condenser as well, it is important to establish the lower threshold concentration of $\mathrm{Cu}^{++}$apt to cause pitting of alloy 5052 and $99.99 \%$ aluminum in seawater.

Each of the variables discussed above can influence the overall corrosion rate by affecting (a) the induction time for pitting and crevice corrosion to initiate or (b) the rate of pit or crevice growth after initiation. The initiation of pits on a free surface is thought to occur only at potentials noble to a well-defined critical potential. 26 This potential represents that at which $\mathrm{Cl}^{-}$ions succeed in disrupting the passive film at local sites, leading to a high rate of dissolution. A pit then nucleates at this site where passivity has broken down. Once initiation has been accomplished, the active anode inside the pit would be expected to supply current for polarizing the metal in the active direction, away from the critical potential. This expectation agrees with field observations that the 5000 series aluminum alloys undergo pitting while their corrosion potentials are several hundred millivolts active to the critical value.13,14

If current theoretical concepts are correct, then the corrosion potential of the metal must rise to the critical value before pitting can initiate. The causal agent for the noble shift is clear if a source of $\mathrm{Cu}^{++}$ions is present, but is uncertain in the absence of copper. One possibility is the rather large transient shifts in potential that are experienced upon initial immersion of any metal into an electrolyte. What is not known is how long the corrosion potential must remain at, or noble to, the critical value in order to nucleate stable pits. If transient potentials do play a role in meeting the requirement for a noble shift in corrosion potential, then the required duration of that noble potential must be brief, as transient potentials decay quickly. The question of duration of the noble potential is one that is not addressed by the experiments described in this report, but which should be the subject of future research. It should be emphasized here that it is only the initiation of pits that is belleved to require a noble shift of the corrosion potential to the critical value. Subsequent propagation of the pits may occur at less noble potentials. 
In contrast, crevice corrosion is not initiated at a specific potential. 27 It occurs at sites of restricted geometry where breakdown of passivity is induced by a localized reduction of oxygen concentration coupled with the accumulation of acid anodic corrosion products such as aluminum chloride. These changes may be brought about through the operation of differential oxygen concentration cells acting at crevices. In an OTEC heat exchanger, crevices may be present at the interfaces between tubes and the tube sheet, or they may be created by deposits of fouling organisms. Although the initiation of pitting and crevice corrosion takes place by different mechanisms as described above, the rate of corrosion subsequent to initiation is controlled in each case by the rate of oxygen reduction or hydrogen evolution at cathodic sites on the metal surface. 26

The first part of the experimental program described in the following sections was to establish the effects on the corrosion potential of dissolved oxygen, $\mathrm{pH}$, temperature, and heavy metal ion concentrations when varied both independently and in combination. Next, effects on the critical pitting potential were determined. The critical potential is already known to be unaffected by dissolved oxygen and heavy metals. ${ }^{25}$ Following this, effects on the initiation of pitting and crevice corrosion were determined by simple immersion tests under controlled conditions. Finally, the rate of corrosion after initiation was determined by measuring the current density upon cathodic polarization of an aluminum electrode either in a galvanic corrosion cell tormed with a suitable anode or by potentiostatic methods. In this final set of experiments, an increase in cathodic current density upon changing the dissŏlved oxygen, $\mathrm{pH}$, etc. from values characteristic of surface water to those of deep water was taken as a measure of increased pit and crevice growth rates under corresponding conditions in the deep ocean. Conversely, a decrease in current density was taken as an indication of decreased pit and crevice growth rates. Most of the data presented are concentrated on alloy 5052 because of the likelihood of its use in OTEC systems, while $99.99 \%$ aluminum serves as a comparative standard or control.

\section{EXPERTMENTAL TECHNIQUES}

- The results reported in this paper were generated on cylindrical laboratory electrodes 2 to $5 \mathrm{~cm}$ long and 0.6 to $0.95 \mathrm{~cm}$ in diameter mounted with 
a Teflon* compression gasket to avold crevice effects. The 5052 alloy electrodes were either machined from 6.35-mm-thick rolled sheet with the rolling direction parallel to the axis of the cylinder or cut from 9.5-mmdiameter extruded rod, both supplied by Reynolds Metals Company. The $99.99 \%$ aluminum was purchased from Materials Research Corporation as 9.5-mm-diameter rod. Table I shows the analyses of these materials provided by the suppliers. In order to obtain reproducible corrosion potentials, it was necessary to strictly control the specimen preparation procedure, and the following sequence was finally adopted. A uniform surface was provided for all electrodes by abrading through 600-grit emery paper followed by pickling for 20 minutes in $20 \%$ nitric acid at 50 to $60^{\circ} \mathrm{C}$, dipping in $1 \mathrm{~N}$ sodium hydroxide for 5 seconds at 50 to $60^{\circ} \mathrm{C}$ and rinsing in distilled water. After pickling, all electrodes were aged for one hour in distllled water before insertion into the test cell. After pickling and again after aging, all electrodes were exánined at a magnification of $2.5 \mathrm{X}$ in a stereo microscope. Any electrode on which pits were found was recycled through the abrasion and pickling steps before using.

Three percent $\mathrm{NaCl}$ solutions were made from distilled water with a resistivity greater than 0.8 megohm and certified grade $\mathrm{NaCl}$ from Fisher Scientific Company. The seawater used was full strength $\left(32^{2}\right.$ to $35^{\circ} \%$ salinity) clean surface water brought to the laboratory in 55-liter polyethylene jugs from 40 to 100 miles east of the mouth of Delaware Bay at two to three-week intervals by the research vessel, Cape Henlopen. The seawater was kept in an air-conditioned compartment on the ship and arrived in the laboratory within 24 hours after removal from the ocean. Once in the laboratory, the water was passed through glass fiber and $0.2-\mu \mathrm{m}$ membrane (Millipore) filters in series to remove detritus and most marine microorganisms and was kept aerated. The aluminum electrodes behaved consistently in this water for about 21 days, but the behavior often began to change during the fourth week.

Corrosion potentials of the test electrodes were measured against a saturated calomel reference electrode ( $\mathrm{SC}$ C ) using a high iujedance Kcithly Mode1 602 electrometer. . The dissolved oxygen concentration was controlled between $0.6 \mathrm{ppm}$ and a $\mathrm{r}$ saturation by bubling the proper air-nitrogen

\footnotetext{
* Trademark. E. I. duPont de Nemours \& Company, Wilmington, DE 19898.
} 
TABLE I

Composition of Alloys Used

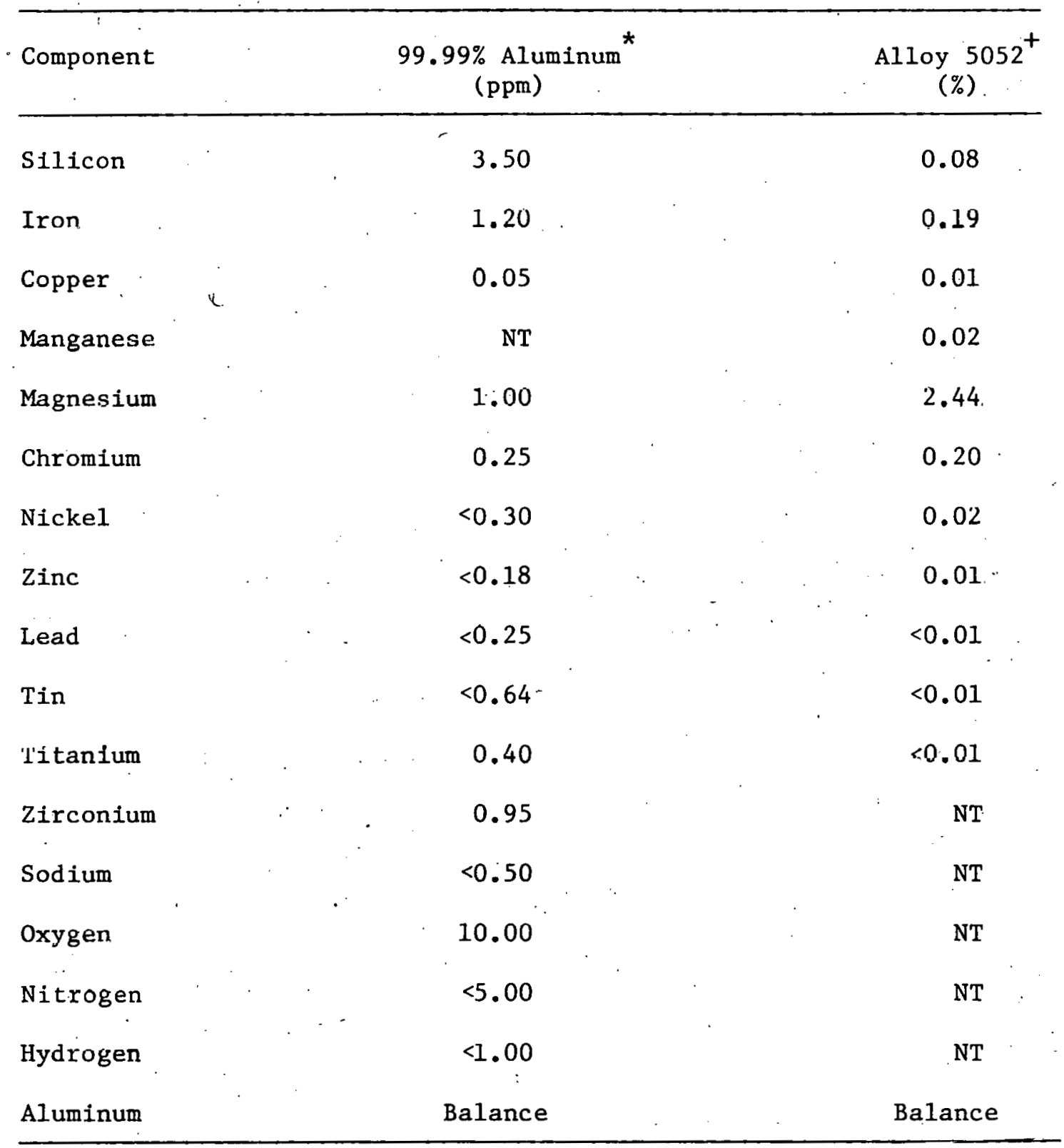

* Material and analysis supplied by Materials Research Corporation. +Material and analysis supplied by Reynolds Metals Company. NT - Indicates component not tested for. 
mixture from a premixed compressed gas cylinder through the electrolyte. Oxygen concentrations were measured using a YSI Model 57 oxygen meter.

The $\mathrm{pH}$ of the electrolyte was controlled either by small additions of $0.1 \mathrm{~N} \mathrm{HCl}$ or $\mathrm{NaOH}(0.01 \mathrm{~N}$ in $3 \% \mathrm{NaCl})$ or by varying the partial pressure of $\mathrm{CO}_{2}$ in the air-nitrogen mixture described above using flow meters. Control was achievable by the acid-base method to better than $\pm 0.05 \mathrm{pH}$ units, and by the $\mathrm{CO}_{2}$ method to $\pm 0.02 \mathrm{pH}$ units. The $\mathrm{CO}_{2}$ method was nearly always used in seawater, while the acid-base method was frequently used in NaCl solutions. The temperature of the test cell was controlled by pumping precooled alcohol through a glass cooling coil inserted into the electrolyte. Precooling was done with. an FTS Systems Model MC260SV Cooling Unit. Control was achieved to better than $0.5^{\circ} \mathrm{C}$ over the temperature range from 4 to $25^{\circ} \mathrm{C}$. In all cases where no specific temperature is given, the test was run at room temperature $\left(22\right.$ to $\left.25^{\circ} \mathrm{C}\right)$.

Pit and crevice initiation tests were run in wide mouth 500-ml Erlenmeyer flasks. For tests at air saturation these were left open to the atmosphere. Tests at lower values of dissolved oxygen were run by bubbling the proper air-nitrogen mixture through a flask fitted 'with a rubber stopper through which were inserted the electrode holder, a gas bubbler for the appropriate nitrogen-oxygen mixture, a salt bridge and a gas outlet tube. For long-term. low oxygen tests, the cell was sealed off by closing a stopcock on the gas inlet tube and plugging the outlet with a closed end glass tube. The fresh1y pickled and aged electrode was immersed in the seawater after the dissolved oxygen reached equilibrium (usually about one hour). Smooth electrodes were used for pit initiation tests. Similar electrodes were used for the crevice tests with the crevice being formed by slipping a single rubber "O-ring" around each electrode.

Corrosion potentials of the test electrodes were measured at least daily on the SCE scale as described above.. Each test was terminated as soon as the white aluminum hydroxide corrosion product was vistble at a pit initiation site on the cylindrical surface of the electrode or adjacent to the rubber "O-ring" creating the test crevice. After the corrosion product was cleaned off by gently brushing under distilled water, corrosion was confirmed by examinartur 111 a sleteu üliroscopc.

Critical pitting potentials and cathodic polarization curves were measured with standard potentiostatic techniques ${ }^{28,29}$ in a 1000-ml six-neck polarization 
flask containing natural seawater or $3 \% \mathrm{NaCl}$ using either a Princeton Applied Research Model 173 or a Wenking Model 70TS1 potentiostat. The final value for the critical pitting potential was taken as the most noble potential that could be maintained for at least 12 hours with neither an increase in current density nor the development of pits on the electrode surface large enough to be observed at a magnification of $25 \mathrm{X}$ in a stereo microscope.

In the cathodic polarization experiments, the freshly pickled and aged electrode was allowed to come to steady state (usually about one hour after immersion) in seawater or $3 \% \mathrm{NaCl}$ in which the $\mathrm{pH}$ and dissolved oxygen were being controlled as described above. No stirring was used during the test other than the mild agitation provided by the gas bulblel. The pH was continuously monitored during each run using a Fisher Accumet Digital pH meter with a combination $\mathrm{pH}$ electrode mounted through one of four outside necks of the flask. Polarization began from the steady-state corrosion potential in discrete steps of $25 \mathrm{mV}$ every five minutes in the active direction until the cathodic current density reached about $10 \mu \mathrm{A} / \mathrm{cm}^{2}$. Sets of cathodic polarization curves at successively more acidic $\mathrm{pH}$ values were run in three different ways: (a) all on the same electrode without repickling between runs of a series, (b) using a freshly pickled and aged electrode for , each new pH value, or (c) using a freshly pickled and aged electrode for each potential level within each curve.

Cathotic polarization was also achleved by the alternative method of connecting the test electrode to a more active metal in a galvanic cell. In these experiments, alloy 5052 was coupled to a zinc electrode through an external circuit. Dissolved oxygen and $\mathrm{pH}$ within the cell were controlled as described previously, and the steady-state cell current was measured using a zero resistance ammeter. The $\mathrm{pH}$ and/or dissolved oxygen of the test solution was then changed and a new steady-state current measured. A steady $\mathrm{pH}$ value was maintained by connecting the test flask to a gravity feed flow-through system having two large reservoirs, one adjusted to the initial and the other. to the final $\mathrm{pH}$ desired. After measurements were made at the initial $\mathrm{pH}$, a stopcock was turned to draw water from the other reservolr at the final $\mathrm{pH}$.

The effects of. heavy metal ion concentrations on both the corrosion potential and on pit initiation were measured by adding the proper concentration directly to the seawater in the test flask. Copper and iron were added as the sulfate salt, and iron was also introduced in one experiment by 
allowing a piece of steel to corrode in the bottom of the test flask for 48 hours. The actual concentration of free $\mathrm{Cu}^{++}$ions was not measured. Corrosion potentials were monitored as described previously, and the presence or absence of pits was confirmed by examination in a low-power microscope.

III. RESULTS

A. The Critical Pitting Potential

The critical pitting potential of alloy 5052 in seawater of salinity $32 \%$, pH 8.2 and $25^{\circ} \mathrm{C}$, was measured by standard techniques and found to be $-0.69 \pm 0.01 \mathrm{~V}$ on the saturated calomel (SCE) scale. In seawater of salinity $35 \%$ or in $3.5 \% \mathrm{NaCl}$, the measured value was slightly more active at $-0.72 \pm 0.015 \mathrm{~V} \mathrm{SCE}$. Measurements were also made at $\mathrm{pH}$ values of 7.8 and 7.5 and at temperatures of 4 and $10^{\circ} \mathrm{C}$, but any differences fell within the experimental error mentioned above. Therefore, since the critical pitting potential is not a function of dissolved oxygen, $25 \mathrm{pH}$ or temperature, it will not vary with depth and can be eliminated from consideration as a factor responsible for increased corrosion rates of aluminum in the deep ocean. B. The Corrosion Potential

Data illustrating how the corrosion potential of alloy 5052 varied with dissolved oxygen at $\mathrm{pH} 8.2$ and with $\mathrm{pH}$ at air saturation over the range in which these variables are found in the open ocean are shown in Figure 3. Decreasing dissolved oxygen made the corrosion potential more active while decreasing $\mathrm{pH}$ made it more noble. The slope of the dissolved oxygen curve was always positive, the corrosion potential becoming more noble at the rate of $50 \pm 5 \mathrm{mV}$ for each $\mathrm{ppm}$ increase in dissolved oxygen. For $\mathrm{pH}$, the slope. was always negative with the corrosion potential becoming more active with rising $\mathrm{pH}$ at the rate of $-37 \pm 5 \mathrm{mV}$ for each $0.1 \mathrm{pH}$ unit down to $\mathrm{pH} 7.5$. Below 7.5 the rate of change decreased because the corrosion potential began to approach the critical pitting potential. The vertical error bars shown in Figure 3, and throughout this report except where stated otherwise, represent the envelope of all data observed rather than the sṭandard deviation.

Corrosion potential measurements were also made at the four combinations of $\mathrm{pH}$ and dissolved oxygen shown in Table II. The corrosion potential of $5052 \mathrm{Al}$ as a function of these conditions is shown in Figure 4. The corrosion potential became more noble with the progression of decreasing $\mathrm{pH}$ and dissolved oxygen pairs shown in Table.II. The data in Figure 4 are a composite of four 
TABLE II

Approximate Ocean Depth Ranges Corresponding to Experimental Combinations of $\mathrm{pH}$ and Dissolved Oxygen

\begin{tabular}{lccc}
\hline $\mathrm{pH}$ & $\begin{array}{c}\text { Temperature } \\
\left({ }^{\mathrm{C}} \mathrm{C}\right)\end{array}$ & $\begin{array}{c}\text { Do } \\
(\mathrm{ppm})\end{array}$ & $\begin{array}{c}\text { Depth } \\
(\mathrm{m})\end{array}$ \\
\hline 8.20 & 15.0 & $7.2-7.5$ & Surface \\
7.85 & 8.5 & 3.1 & 150 to 200 \\
7.65 & 7.0 or & 1.3 & 350 to 380 or \\
7.50 & 3.0 & & 1060 to 1300 \\
& $4.0-5.0$ & 0.6 & 500 to 900 \\
\hline
\end{tabular}

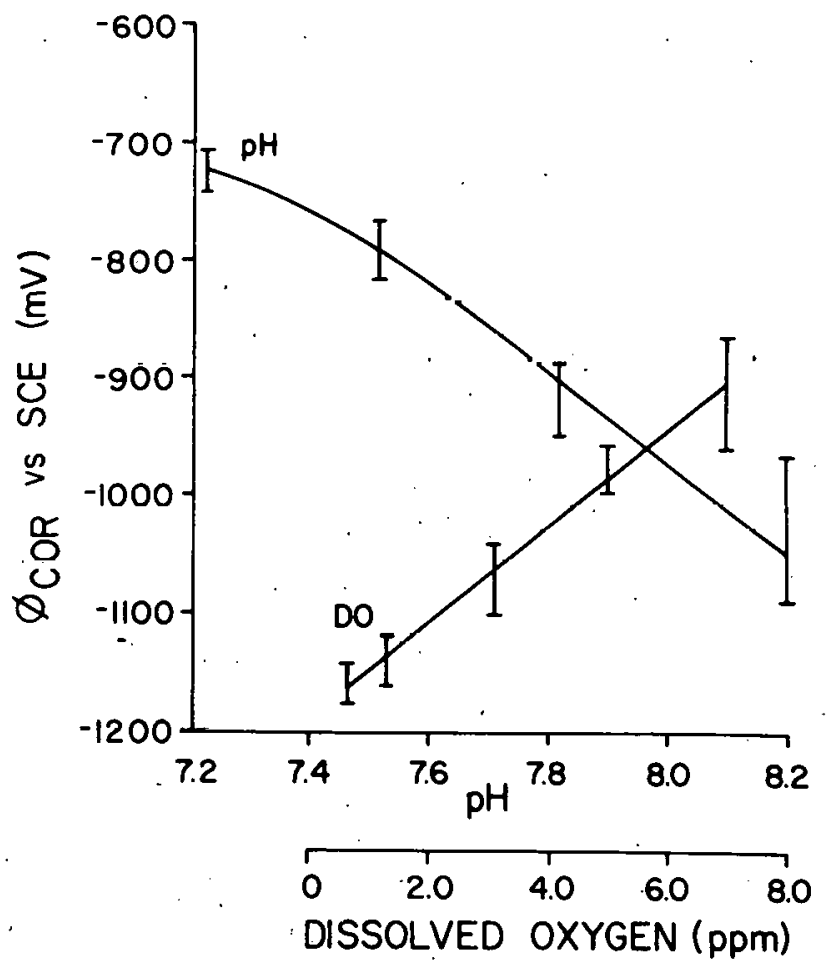

Figure 3. Effect of Do at $\mathrm{pH} 8.2$ and of $\mathrm{pH}$ at Air Saturation on the Corrosion Potential of Alloy 5052 in Seawater

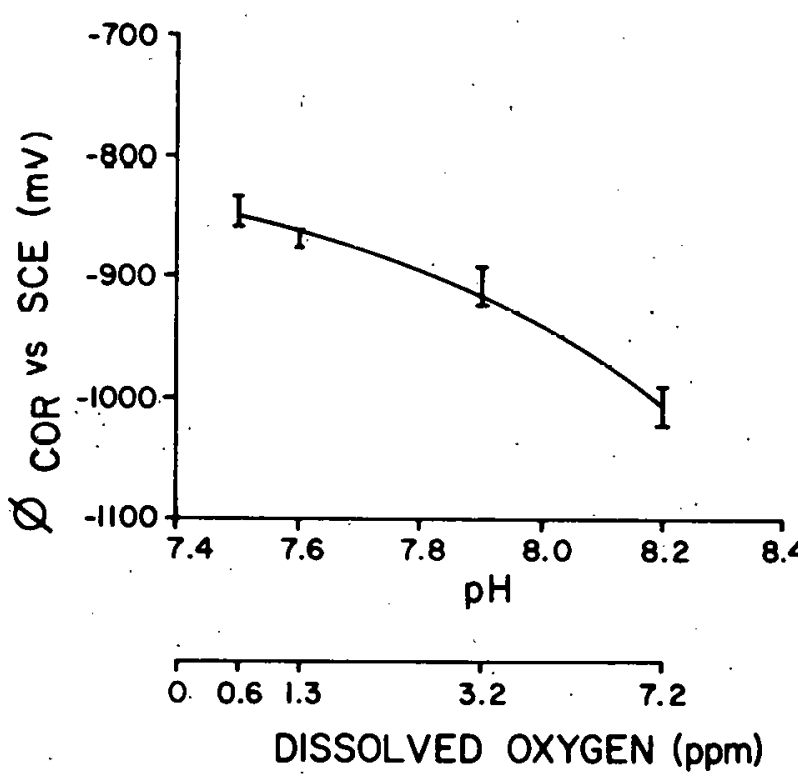

Figure 4. Effect of Combinations of $\mathrm{pH}$ and DO Found in the Deep Pacific Ocean (See Figure 2 and Table. II) on the Corrosion Potential of Alloy 5052 in Seawater 
individual runs, whose average corresponding to the curve drawn through the data is similar in shape to the $\mathrm{pH}$ curve of Figure 3. As is seen in Figure 3, the $\mathrm{pH}$ and DO effects were in opposition, but Figure 4 shows that the $\mathrm{pH}$ effect predominated when both were varied together. In these tests, the corrosion potential was always active to the critical pitting potential. This is in contrast to the case of decreasing the $\mathrm{pH}$ alone as shown in Figure 3 , where the critical pitting potential was sometimes approached during the experiment.

The effect of decreasing temperature on the corrosion potential of alloy 5052 in air-saturated seawater at $\mathrm{pH}$ values of 7.7 and 8.2 is shown in Figure 5. As was the case for $\mathrm{pH}$ alone, a decrease in temperature, with all other factors held constant, causes the corrosion potential to shift in the noble direction: At air saturation, a decrease in temperature to $4^{\circ} \mathrm{C}$ is alone sufficient to raise the corrosion potential to within $20 \mathrm{mV}$ of the critical pitting potential at $\mathrm{pH} 7.7$, or to within $150 \mathrm{mV}$ at $\mathrm{pH} 8.2$. Decreasing the dissolved oxygen at the same time as temperature, however, reduces the amount of noble shift. The effect of a decrease in $\mathrm{pH}$ upon the corrosion potential of alloy 5052 in air-saturated $3 \% \mathrm{NaCl}$ is shown. in Figure 6 . The shift in the noble direction with decreasing $\mathrm{pH}$ is about half that for natural seawater (see Figure 3) but does not disappear entirely. The corrosion potential at $\mathrm{pH} 8.2$ is more noble than that in seawater at the same $\mathrm{pH}$, while at $\mathrm{pH} 7.2$ the corrosion potential is more active.

The corrosion potential of $99.99 \%$ aluminum in seawater as a function of $\mathrm{pH}$ at air saturation and dissolved oxygen at $\mathrm{pH} 8.2$ is shown in Figure 7 . The direction of potential shift with decreasing $\mathrm{pH}$ and dissolved oxygen was the same as for alloy 5052 but the effect was not as large. The slope of the $\mathrm{pH}$ curve for $99.99 \%$ aluminum was $-18 \pm 3 \mathrm{mV}$ per $0.1 \mathrm{pH}$ unit and that of the dissolved oxygen curve was $+12 \pm 3 \mathrm{mV}$ per ppm.

Several anions and cations were added to $3 \% \mathrm{NaCl}$ in an attempt to make the corrosion potential in that solution behave as it does in natural seawater. Nitrates, silicates and phosphates were added as the sodium salt at concentrations up to $80 \mu$ moles per liter of solution. These produced no reproducible effect that was not within the experimental error shown in Figure 6. Additions of $140 \mathrm{ppm} \mathrm{HCO}^{-3}$ ion as the sodium salt, however, made the corrosion potential more noble at $\mathrm{pH} 7.2$ and more active at $\mathrm{pH} 8.2$. At all $\mathrm{pH}$ values between and including these two extremes, the corrosion 


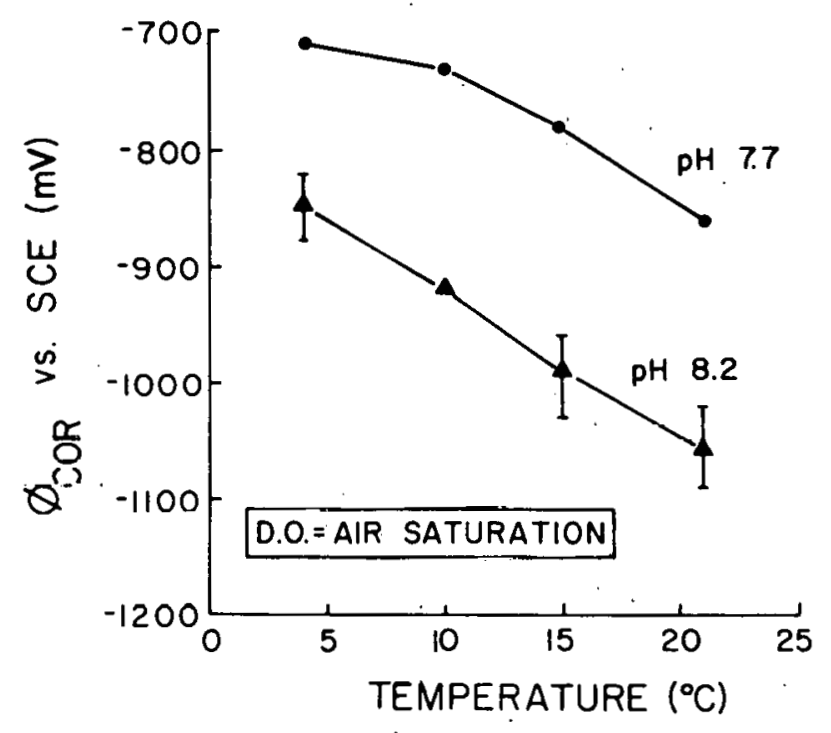

Figure 5. Effect of Temperature at Two $\mathrm{pH}$ Values on the Corrosion Potential of Alloy 5052 in Airsaturated Seawater

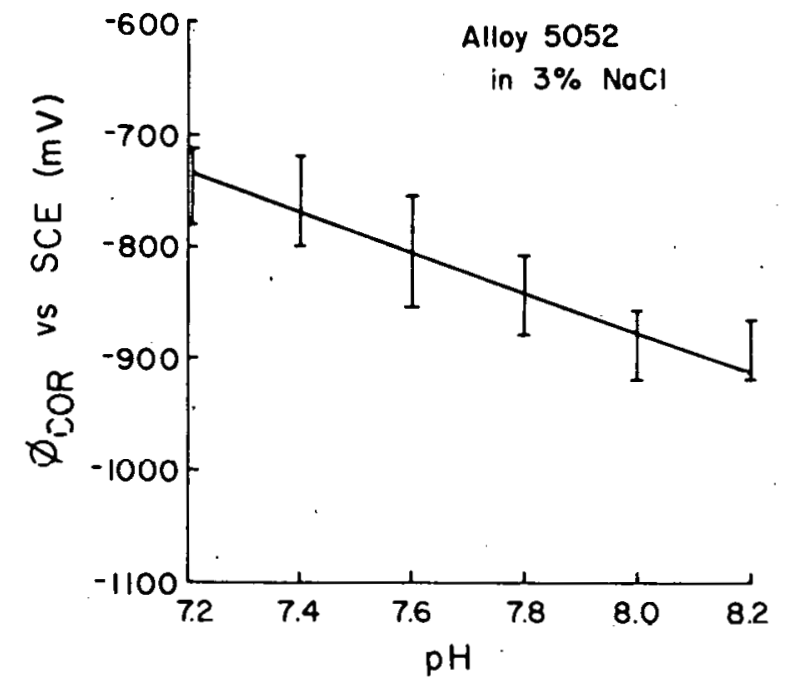

Figure 6. Effect of $\mathrm{pH}$ on the Corrosion Potential of Alloy 5052 in $3 \% \mathrm{NaCl}$

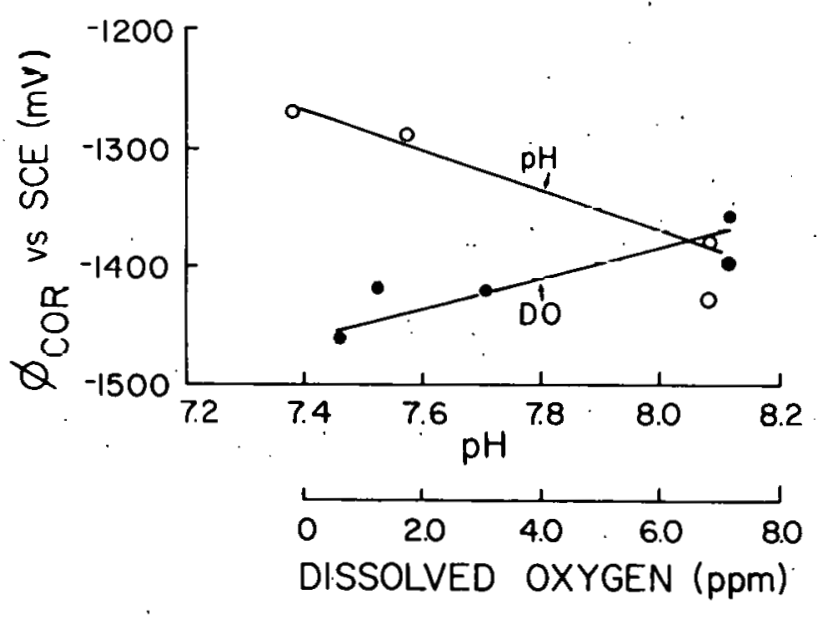

Figure 7. Effect of DO at $\mathrm{pH} 8.2$ and of $\mathrm{pH}$ at Air Saturation on the Corrosion Potential of $99.99 \%$ Aluminum in Seawater 
potential closely reproduced that for alloy 5052 in natural seawater (see Figure 3). Additions of calcium to $40 \mathrm{ppm}$ and magnesium to $1270 \mathrm{ppm}$ both as the chloride produced no effect on the corrosion potential when added singly. Neither did simultaneous additions of calcium and magnestum alter the effect of $\mathrm{HCO}_{3}{ }^{-}$.

\section{Pit and Crevice Initiation}

The length of exposure to natural seawater necessary to initiate pitting and crevice corrosion was measured as a function of $\mathrm{pH}$ and dissolved oxygen concentration of the seawater. For alloy 5052, both pitting and crevice corrosion initiated on some of the samples in less than 15 days at $\mathrm{pH} 8.2$, and the initiation times became shorter and more consistent as the $\mathrm{pH}$ decreased from 8.2 to 7.4. This is illustrated in Figures $8 \mathrm{a}$ and $8 \mathrm{~b}$ where the solid points represent the average of all pit or crevice initiation times for those electrodes on which corrosion began in less than 30 days at a given $\mathrm{pH}$, and the error bars represent the standard deviation. As soon as pitting had initiated, white specks of corrosion product were visible to the naked eye on the electrode surface and small spherical pits were observable under a low-power stereo microscope. Each time pitting was visible on the surface, the potential of the electrode had shifted to $-0.7 \pm 0.02 \mathrm{~V}$ on the saturated calomel scale. This agrees closely with our measurements of the potentiostatic critical pitting potential of alloy 5052 under the same experimental conditions. All tests represented by Figure 8 were stopped after corrosion started or after 30 days, whichever was shorter. At $\mathrm{pH} 8.2,70 \%$ of both the pit and crevice tests had not begun to corrode within 30 days. At $\mathrm{pH} 7.6,12 \%$ of the pit initiation tests and one of the crevice initiation tests did not corrode within 30 days, but all tests, both pit and crevice, at $\mathrm{pH} 7.8$ and 7.4 initiated within that time period. Several of the pit and crevice tests at $\mathrm{pH} 8.2$ that survived the first 30 days without initiation were continued for longer times, and had still not begun to corrode after 12 months of continuous immersion.

Pit and crevice initiation times on alloy 5052 were prolonged at pH 8.2 and dissolved oxygen concentrations below air saturation. Corrosion did not initiate within the 30-day test period on any of the electrodes at dissolved oxygen concentrations of $3.1,1.3$, or $0.6 \mathrm{ppm}$. From these results, it is evident that decreased oxygen concentration in the deep ocean cannot be 


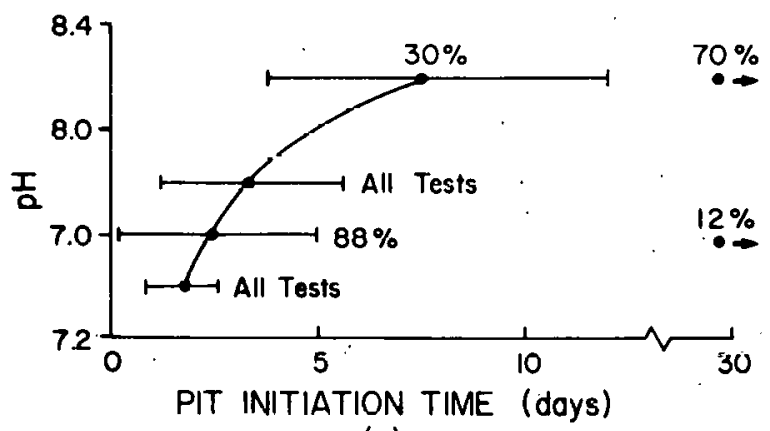

(a)

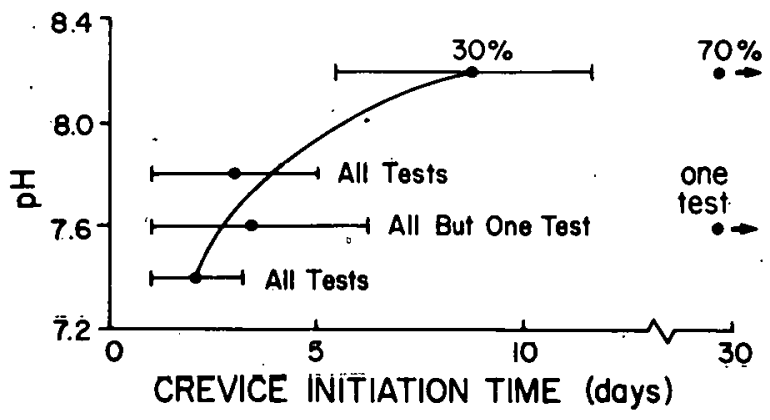

(b)

Figure 8. Effect of $\mathrm{pH}$ on Initiation of Pitting and Crevice Corrosion of Alloy 5052 in Air-saturated Seawater. Horizontal error bars represent the standard deviation. 
responsible for a decrease in pit or crevice initiation times, while a decrease in $\mathrm{pH}$ could produce that effect.

In contrast to the behavior of alloy 5052, $99.99 \%$ aluminum resisted pit initiation for more than 30 days at dissolved oxygen levels from air saturation to $0.6 \mathrm{ppm}$ and at $\mathrm{pH}$ values from 8.2 to 7.4 . The corrosion potentials of all $99.99 \%$ aluminum electrodes remained active at about $-1.4 \pm 0.05 \mathrm{~V} \mathrm{SCE}$, and the surface was found to be free of pits under a stereo microscope at a magnification of $25 \mathrm{X}$. One test in air-saturated seawater at $\mathrm{pH} 8.2$ was run for more than 18 months. A heavy oxide film built up but there is still no sign of either pitting or crevice attack.

Crevice initiation tests have been run on $99.99 \%$ aluminum at $\mathrm{pH}$ values of $8.2,7.8,7.6$, and 7.4 , and,crevice initiation has not taken place within 30 days at $\mathrm{pH}$ values more basic than 7.6. One test out of five at $\mathrm{pH}$ 7.6 initiated in one day, and three tests out of six at $\mathrm{pH} 7: 4$ initiated in 1,3 , and 33 days, respectively.

\section{Heavy Metal Sensitivity}

In clean seawater wịth residual $\mathrm{Cu}^{++}$concentration of about $0.2 \mathrm{ppb}$, as measured by atomic absorption spectrometry, alloy 5052 pitted within 15 days (Figure 8). Figure 9 shows that addition of as little as $30 \mathrm{ppb} \mathrm{Cu}^{++}$as. $\mathrm{CuSO}_{4}$ will reduce pit initiation times even further, but this is probably not of engineering signiftcance to OTEC. In contras, $1,99.99 \%$ aluminum, which does not pit in clean seawater, can be made to pit in less than one day by the addition of $0.2 \mathrm{ppm} \mathrm{Cu}^{+}$. The long-term lower threshold of $\mathrm{Cu}^{++}$ for pitting of $99.99 \%$ aluminum is not well defined by the data in Figure 9 , but appears to be about $40 \mathrm{ppb}$. It is possible that the threshold may be even lower. A series of long-term tests in air-saturated seawater at $\mathrm{pH} 8.2$ and $\mathrm{Cu}^{++}$ion concentrations of 1,4 , and $10 \mathrm{ppb}$ showed no pitting after 6 months but by 18 months some broad shallow pitting had developed sporadically at all three concentrations. These tests are inconclusive but they may indicate that even $1 \mathrm{ppb}$ of copper is too much over a long-term immersinn. These values are considerably lower than the $0.1 \mathrm{ppm}$ that would have been predicted from work in fresh waters. These data may be significant if pure aluminum is considered as a cladding material for OTEC heat exchanger surfaces, or if it is decided to use 90-10 copper-nickel screening on the warm water intake. It was expected that $\mathrm{Fe}^{++}$tons would also shift the corrosion potential in the noble direction and accelerate pit initiation. 


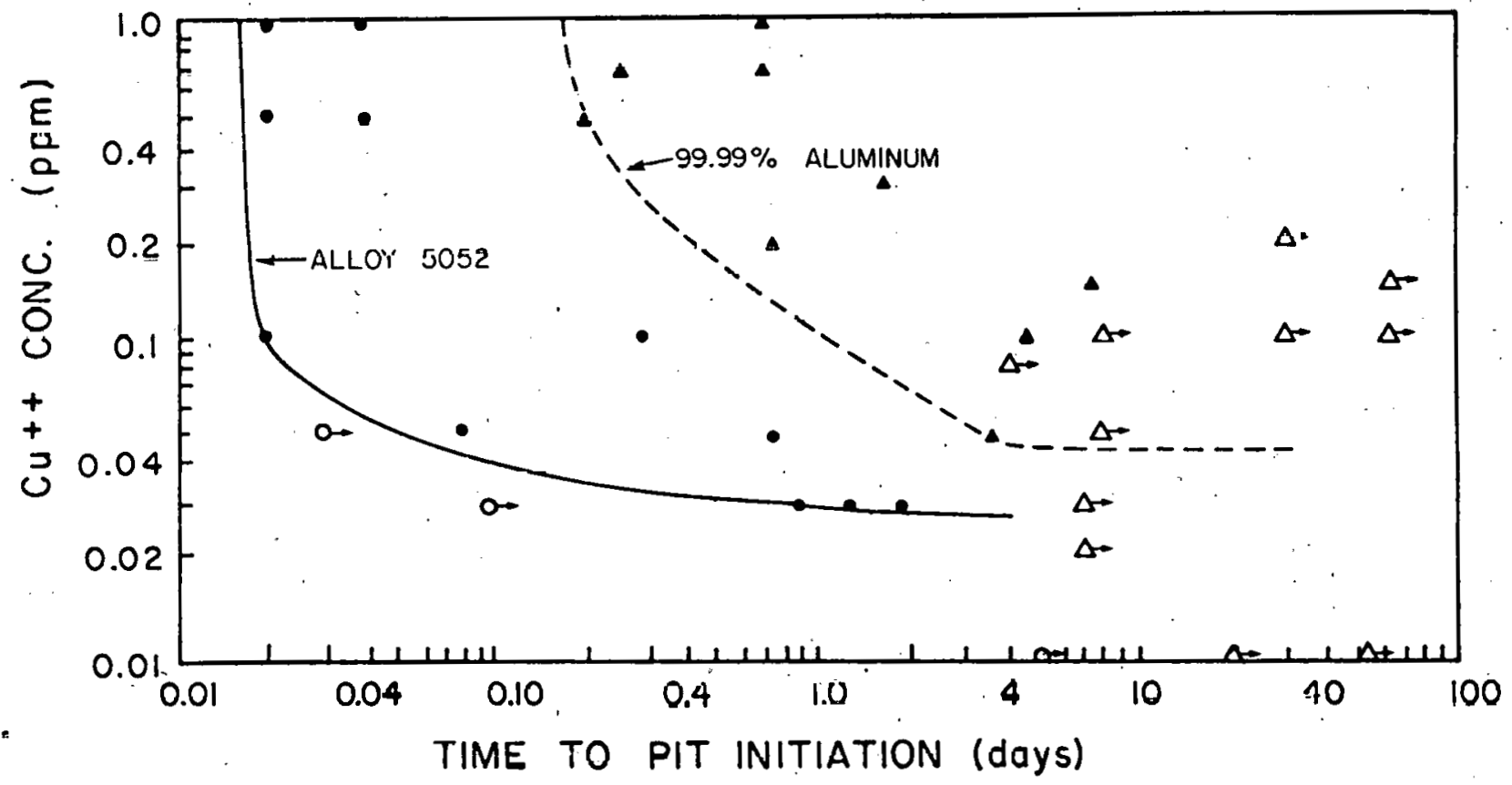

Figure 9. Effect of Addition of $\mathrm{Cu}^{++}$Ion to Seawater on the Time for Initiation of Pits on Alloy 5052 and $99.99 \%$ Aluminum. Solid points represent conditions under which pitting started, and open points, conditions under which no pitting occurred. 
Addition of up to $5 \mathrm{ppm}$ of $\mathrm{Fe}^{+H}$, both as the sulfate and from a piece of corroding steel, however, had no measurable effect on the corrosion potential of $99.99 \%$ Al over a period of three days. Effects of copper and iron on accelerating the growth rate of pitting have not yet been studied.

E. Pit and Crevice Growth

1. Alzoy 5052 in Secwater

a. Effect of Dissolved Oxygen at $\mathrm{pH} \mathrm{8.2.} \mathrm{The} \mathrm{cathodic} \mathrm{polarization}$ of alloy 5052 was measured at $\mathrm{pH} 8.2$ as a function of dissolved oxygen concentration by both the galvanic couple (Figure 10) and cathodic polarization (Figure 11) techniques. In both Figures 10 and 11 , it is evident that decreasing the dissolved oxygen while maintaining everything else'constant leads to a decrease in the cathodic current density. Thus a decrease in dissolved oxygen in the deep ocean cannot be responsible for an acceleration of either pit or crevice propagation rates. In contrast to this behavior, is the effect of small changes in $\mathrm{pH}$.

b. Effect of $\mathrm{pH}$ at Air Saturation. The effect of $\mathrm{pH}$ on the cathodic polarization of 5052 aluminum was determined by both the galvanic couple and potentiostatic methods. In the galvanic couple tests, the steady-state current density of alloy 5052 coupled to zinc in seawater was first determined at $\mathrm{pH}$ 8.2. The $\mathrm{pH}$ was then changed to a more acidic value, and a new steady-state current density was measured. Figure 12 shows the ratio of the current density at the test $\mathrm{pH}$ to that at $\mathrm{pH} 8.2$ as a function of the test $\mathrm{pH}$. Fach point. plotted is the average of several runs. Individual ratios varied from 1.12 to 5.29 but were always greater than one, and were steady over the one to two-hour time period over which each test was run. This result was independent of the direction of the $\mathrm{pH}$.change. If the test $\mathrm{pH}$ was established first, then a reduction in current density was observed upon changing the $\mathrm{pH}$ to 8.2 .

In order to eliminate the possibility that the observed changes were taking place on the zinc electrode rather than on the aluminum, these experiments were run with an alumina thimble around the zinc electrode to isolate it from the $\mathrm{pH}$ change. The increase in current observed upon decreasing the pH from 8.2 to 7.6 is shown in Figure 13. The experiment was then repeated with the thinble around the aluminum electrode, and apart from a brief transient there was no lasting change in current upon decreasing the $\mathrm{pH}$. 


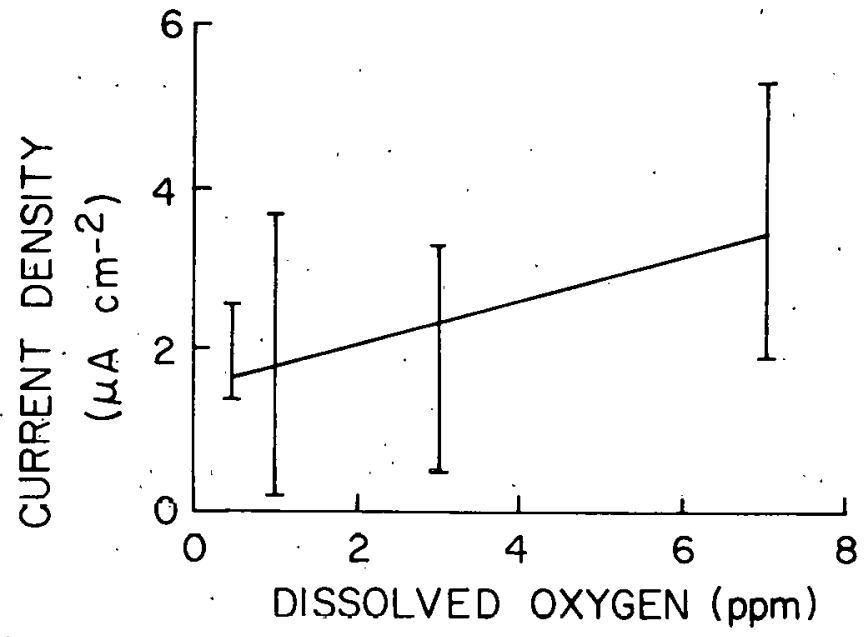

Figure 10. Effect of DO on the Cathodic Current. Density on Alloy 5052 Coupled to Zinc in Seawater at $\mathrm{pH} 8.2$

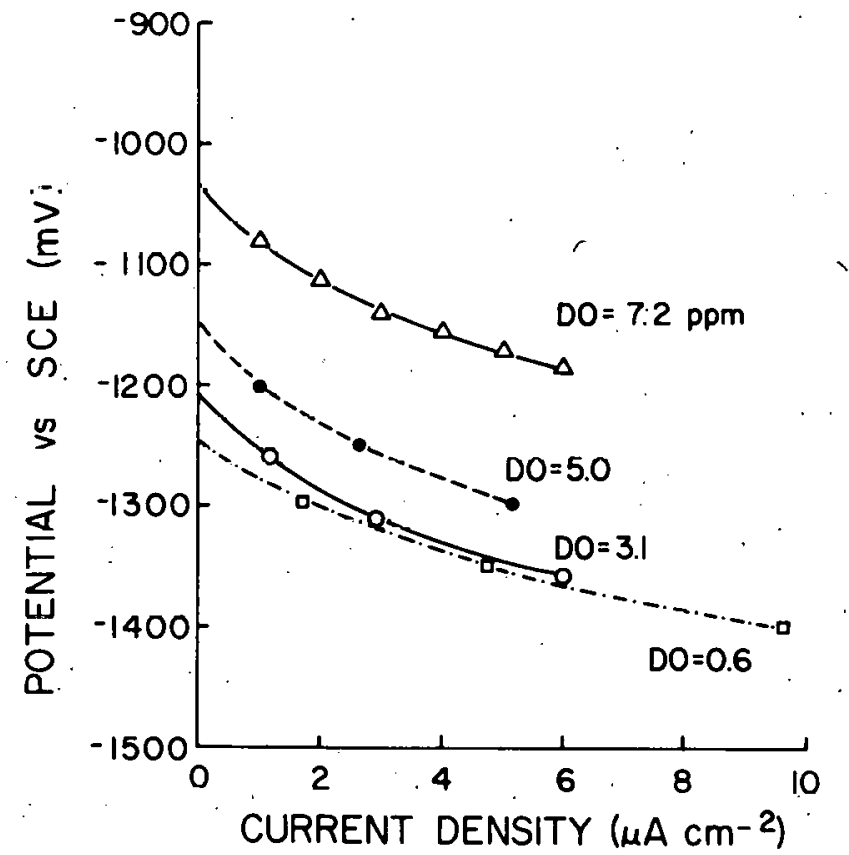

Figure 11. Effect of Do on the Cathodic Polarization of Alloy 5052 in Seawater at $\mathrm{pH} 8.2$ 


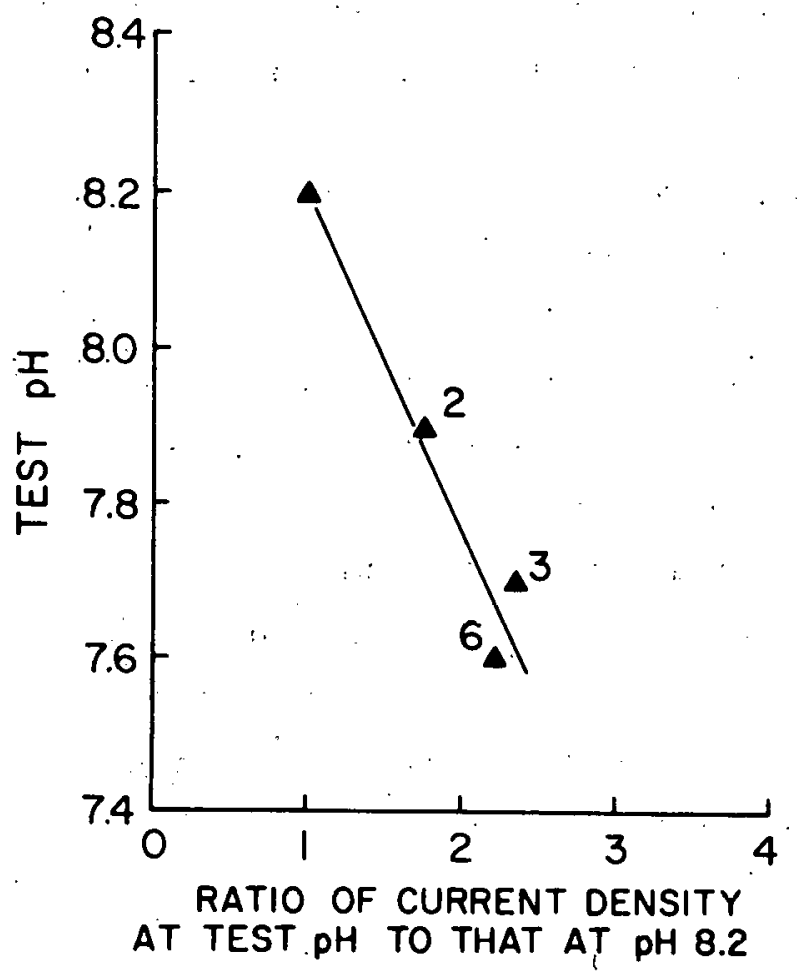

Figure 12. Increase in Current Density with Decreasing $\mathrm{pH}$ on 5052 Aluminum Coupled to Zinc in Air-saturated Seawater. Numerals beside each point represent the number of runs for which that point is the average.

Figure 13. Influence of Sudden $\mathrm{pH}$ Change on the Current Density for an Alloy 5052-Zinc Galvanic Couple in Seawater with the $\mathrm{Zn}$ and A1 Electrodes Alternately Shielded from the $\mathrm{pH}$ Change

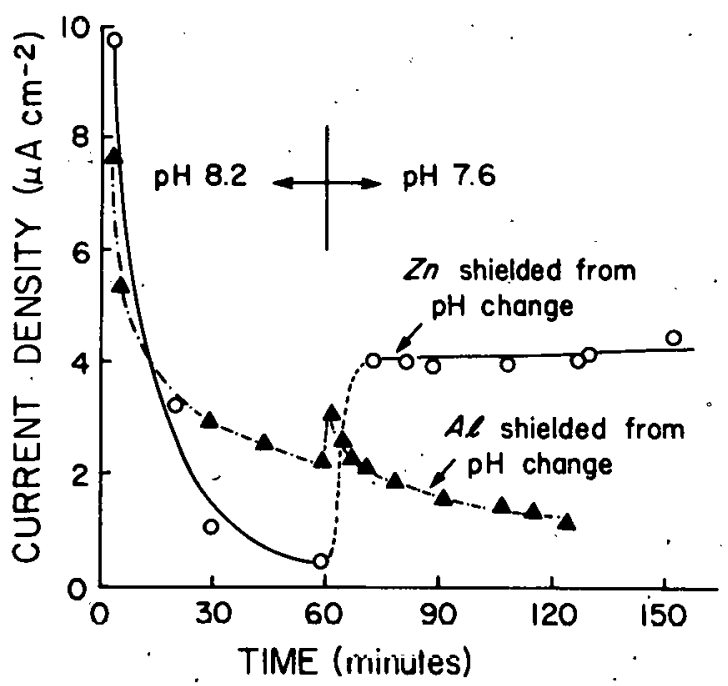


The $\mathrm{pH}$ effect was also observed by the potentiostatic method. Figure 14 shows a series of cathodic polarization curves of alloy 5052 in natural seawater all run on the same electrode at successive $\mathrm{pH}$ values of $8.2,7.8,7.5$, and 7.2 using $\mathrm{HCl}$ control. Note that as the $\mathrm{pH}$ is decreased, the corrosion potential shifts in the noble direction (in agreement with Figure 3), and that each curve is progressively shifted toward higher current densities for any given, value of the potential. Figure 15 shows the experimental variability encountered when a freshly pickled electrode is used for each curve at $\mathrm{pH}$ values of 8.2 and 7.2. The error bars represent the scatter in potential that was observed over at least five curves run under the same conditions. Also shown on Figure 12 are data (open points) taken by using a freshly pickled and aged electrode for each potential level within each curve. These data fall within the experimental scattor for curves run on a single electrode. In comparing Figures 14 and 15 , note that the curves for pH 7.2 and 8.2 converge slower when succeeding curves are all run on the same electrode. This effect is probably an experimental artifact produced as each pH condition effects the next curve in the sequence. For the most accurate and reproducible data, separate electrodes should be used for each curve as was done in Figure 15. The $\mathrm{pH} 7.2$ curve was repeated using both $\mathrm{HCl}$ additions and $\mathrm{CO}_{2}$ partial pressure to control the $\mathrm{pH}$. At current densities less than about $4 \mu \mathrm{A} \mathrm{cm}^{-2}$, the differences fell within experimental error (Figure 16) and either method of pH control can he used,

c. Synergistic Effects of Oxygen, $\mathrm{pH}$ and Temperature. The strong systematic effect of $\mathrm{pH}$. on: the cathodic polarization behavior of alloy 5052 at air saturation was somewhat modified at lower dissolved oxygen concentrations. The effect of reducing the dissolved oxygen to 3.0 is shown in Figure 17, in which the shaded areas represent the envelope of the data from Figure 15 for comparison. The data at pH 7.2 are not altered by the dissolved oxygen decrease, but the corrosion potentials at $\mathrm{pH} 7.7$ and 8.2 are made more active. As the dissolved oxygen decreased still further to $0.6 \mathrm{ppm}$, the corrosion potentials became even more active. In addition, the slopes of the cathodic polarization curves at low current densities and low $\mathrm{pH}$ values became steeper.

When temperature was included as a variable in the cathodic polarization experiments, the results shown in Figures 18 through 20 were obtained. At $7.2 \mathrm{ppm}$ dissolved oxygen and $4^{\circ} \mathrm{C}$, the corrosion potentials at all pH values became noble (Figure 18), as would be expected from Figure 5. 


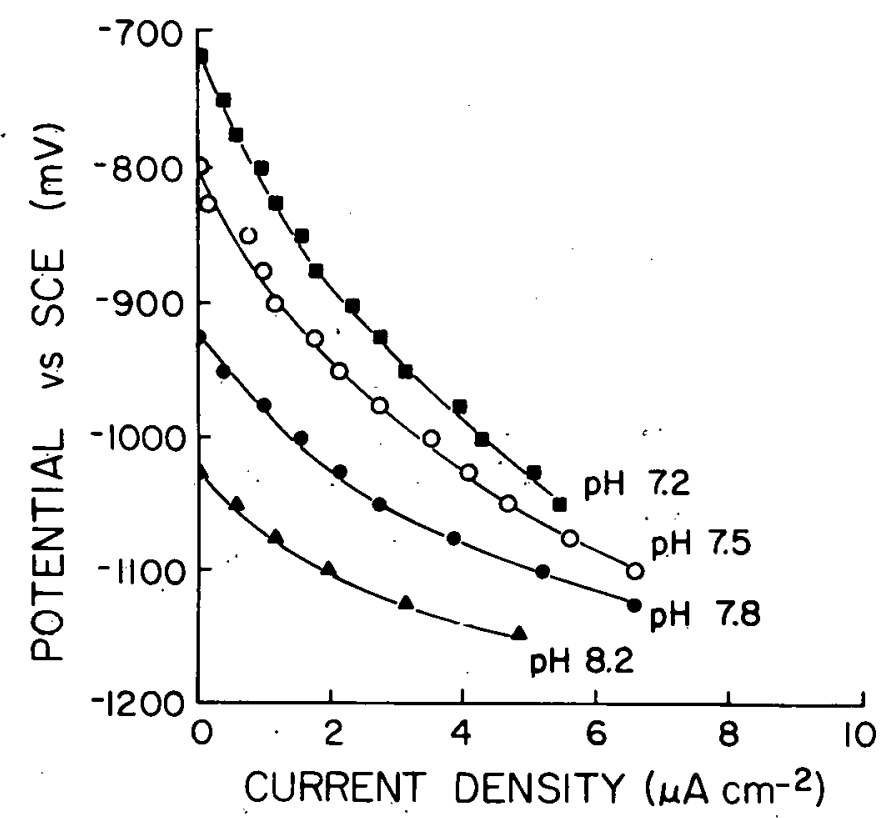

Figure 14. Influence of $\mathrm{pH}$ on Cathodic Polarization of Alloy 5052 in Air-saturated Seawater. Al1 curves were run in succession on the same electrode.

Figure 15. Experimental Variability. of the Influence of $\mathrm{pH}$ on Cathodic Polarization when Using (1) a Separate Electrode at Each pH Value or (2) a Separate Electrode ... at Each Potential Level within Each Curve' (Open Points)

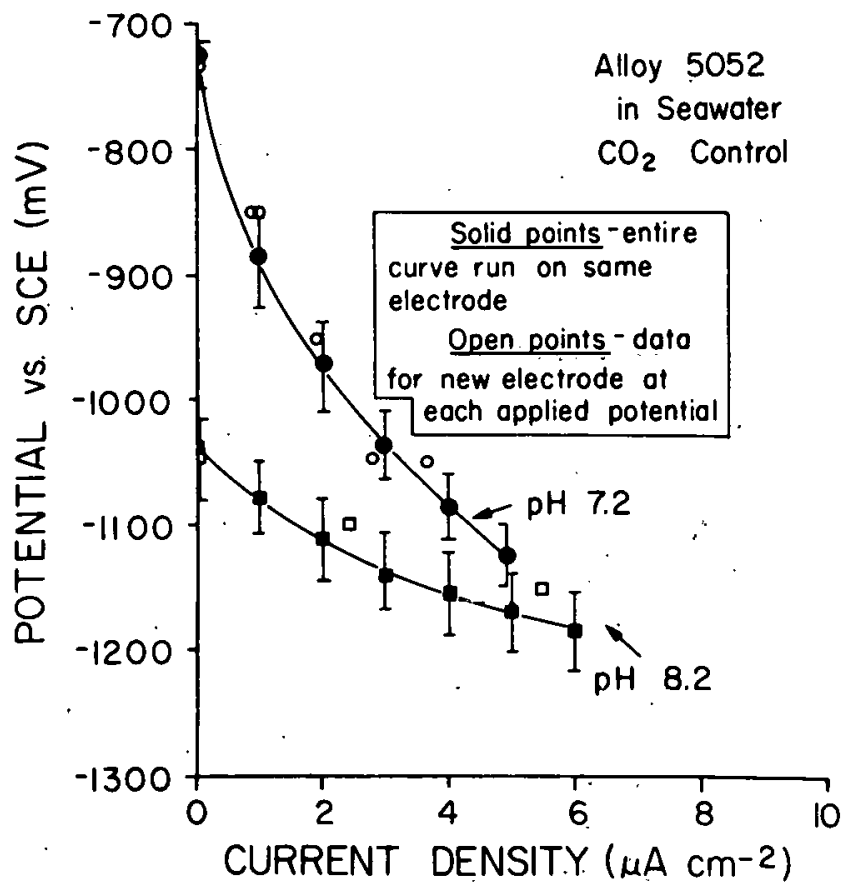



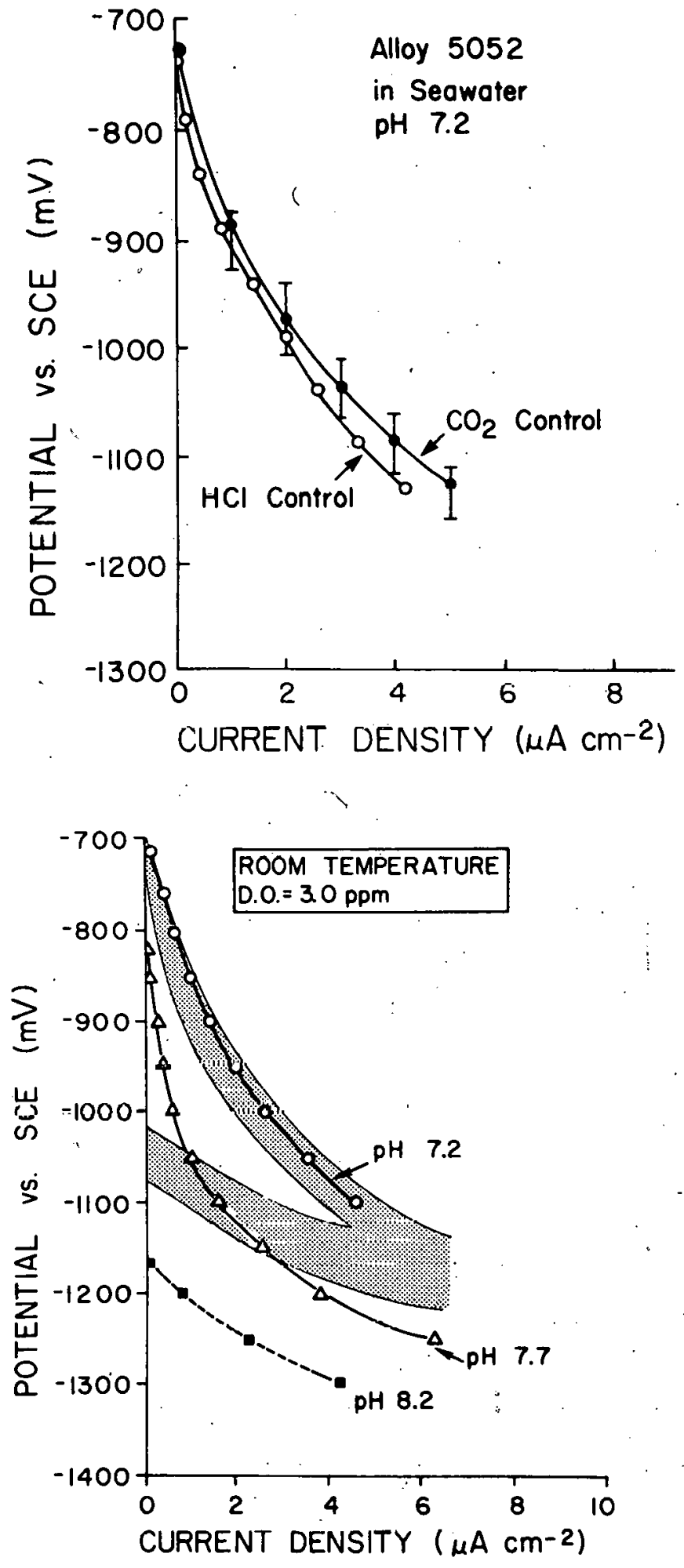

Figure 17. Effect of $\mathrm{pH}$ on Cathodic Polarization of Alloy 5052 in Seawater with $3 \mathrm{ppm}$ DO at $23 . \pm 2{ }^{\circ} \mathrm{C}$. Shaded area represents the envelope of data from Figure 15.
Figure 16. Comparison of Cathodic Polarization Data in Airsaturated Seawater at $\mathrm{pH} 7.2$ as Controlled by HCl Additions and by $\mathrm{CO}_{2}$ Partial Pressure

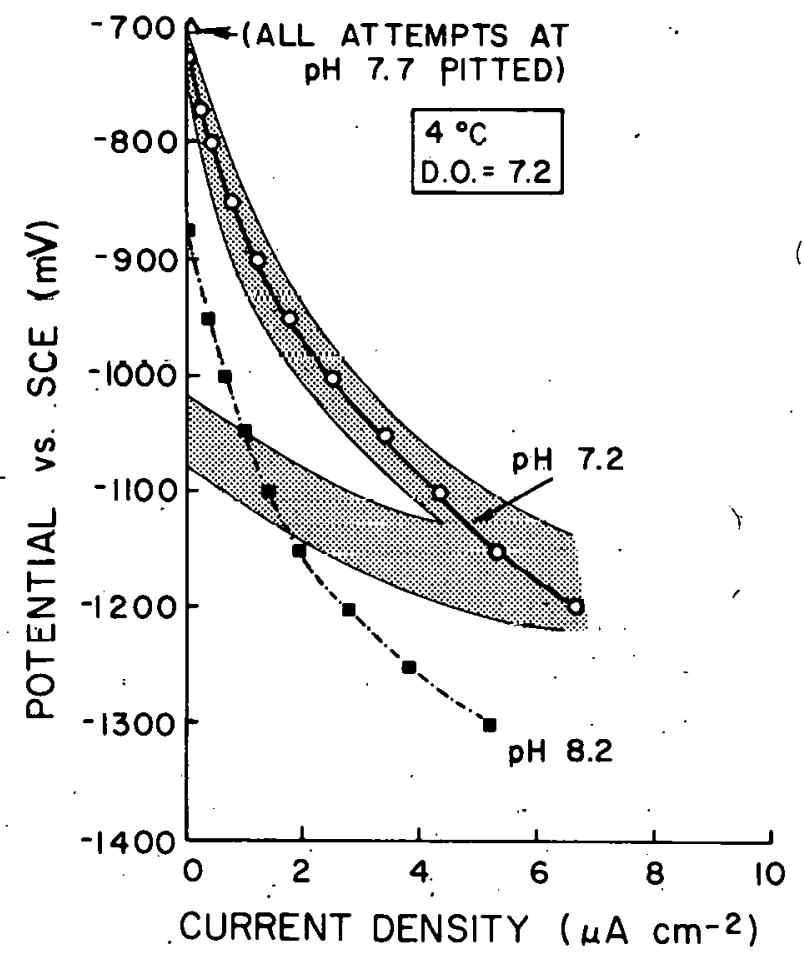

Figure 18. Effect of $\mathrm{pH}$ on Cathodic Polarization of Alloy 5052 in Seawater with $7.2 \mathrm{ppm}$ DO at $4.0^{\circ} \mathrm{C}$. Shaded area represents the envelope of data from Figure 15. 


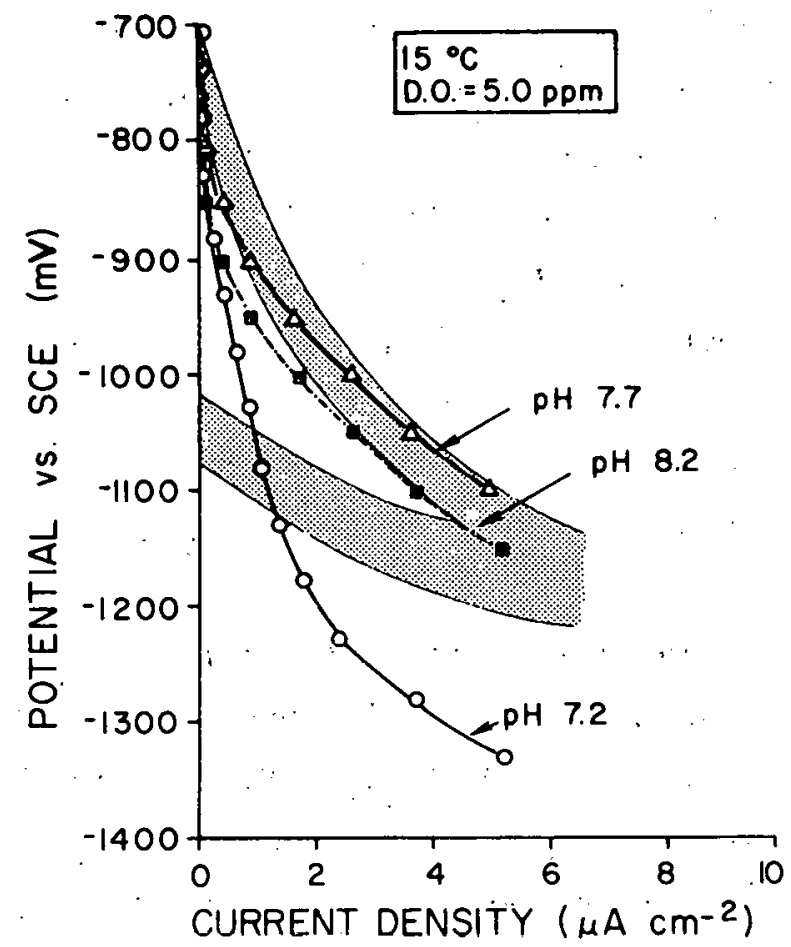

Figure 19. Effect of $\mathrm{pH}$ on Cathodic Polarization of Alloy 5052 in Seawater with 5.0. ppm DO at $15^{\circ} \mathrm{C}$. Shaded area represents the envelope of data in Figure 15.

Figure 20. Effect of $\mathrm{pH}$ on Cathodic Polarization of Alloy 5052 in Seawater with $0.6 \mathrm{ppm}$ DO at $4.0^{\circ} \mathrm{C}$. Shaded area represents the envelope of data in Figure 15:

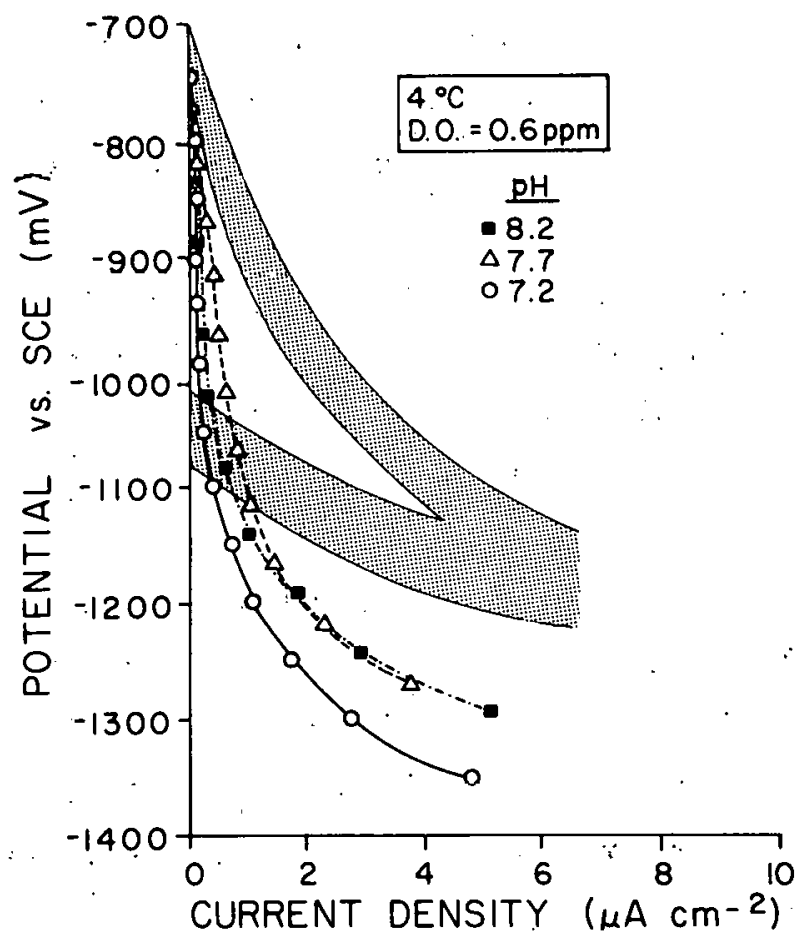


This proved to be a highly corrosive set of conditions, especially at low pH. The envelope of the data from Figure 15 is shown for comparison. While the curve at $\mathrm{pH} 7.2$ is not changed by the low temperature, at $\mathrm{pH} 7.7$ the combination of reduced $\mathrm{pH}$ and low temperature caused the corrosion potential to exceed the critical pitting potential. On every trial attempted at DO $7.2 \mathrm{ppm}, \mathrm{pH} 7.7$ and $4^{\circ} \mathrm{C}$, the corrosion potential rose to the critical value within one-half hour after immersion in the test cell, and pitting began on the cylindrical surface of the electrode before it had equilibrated sufficiently to begin polarization. It is not known why conditions were more corrosive at $\mathrm{pH} 7.7$ than at $\mathrm{pH} 7.2$.

Figure 19 shows the cathodic polarization data at intermediate values of temperature $\left(15^{\circ} \mathrm{C}\right)$ and disṣolved oxygen $(5.0 \mathrm{ppm})$. This set of conditions was nearly as corrosive as that at $\mathrm{pH} 7.7$ in Figure 18 . The lower temperature compensated for the reduced dissolved oxygen, and again the corrosion poțentials were near the critical pitting potential. At $\mathrm{pH} 7.2$, the corrosion potential often reached the critical value causing pitting to occur before the run could be started as described above. The curve at $\mathrm{pH} 7.2$ in Figure 19 appears to be anomalous. The corrosion potential is very noble, and one would expect the curve to show higher current densities at all potentials (that is, have a shallower slope) than that at $\mathrm{pH} 7.7$. It is suggested that pitting began just as this run was started, and the current supplied by the active pit tended to polarize the electrode in the same dileclun as the potentiostat, thereby making the applied potentiostatic current artificlally low. The data at both low temperature $\left(4^{\circ} \mathrm{C}\right)$ and low oxygen ( $0.6 \mathrm{ppm}$ ) are shown in Figure 20. Such conditions appear to be less corrosive than those of Figures 18 and 19. The corrosion potentials are less noble due to the very low oxygen, and the curves at all $\mathrm{pH}$ values'show rapid polarization.

Figure 21 summarizes cathodic polarization data approximating three of the open ocean conditions shown in Table II (see Figure 2) as well as the hypothetical $15^{\circ} \mathrm{C}, 5.0 \mathrm{ppm}$ DO, $\mathrm{pH} 7.7$ curve from Figure 19. Note that at any given potential, noble to $-1100 \mathrm{mV} \mathrm{SCE}$, the current density is highest for the two curves at the intermediate values of temperature, pH and oxygen.

In Table III is presented a summary of all the cathodic polarization data from Figures 15 through 21 plus several other DO, pH and 


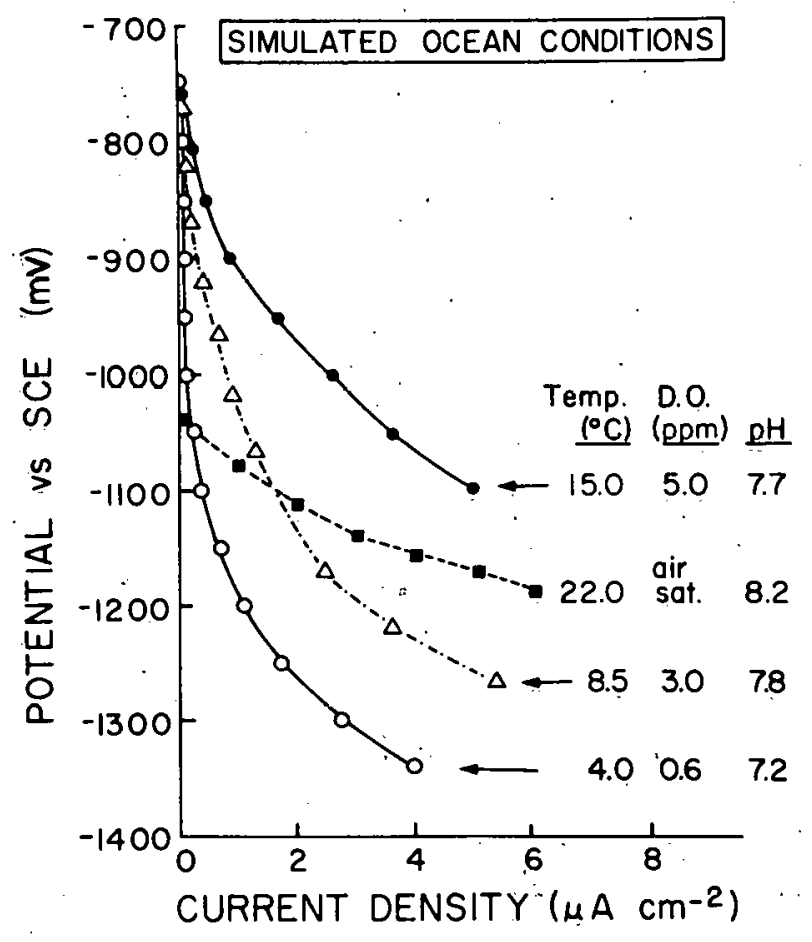

Figure 21. Cathodic Polarization of Alloy 5052 in Seawater at Combinations of $\mathrm{pH}$, DO and Temperature in the Deep Ocean (See Figure 2 and

- Table II) 
TABLE III

Summary of Polarization Data for Alloy 5052

\begin{tabular}{|c|c|c|c|c|}
\hline Temperature $\left({ }^{\circ} \mathrm{C}\right)$ & DO (ppm) & $\mathrm{pH}$ & $\begin{array}{c}\text { Corrosion } \\
\text { Potential } \\
\quad(m V \text { SCE) }\end{array}$ & $\begin{array}{l}i\left(\mu \mathrm{A} \mathrm{cm}^{-2}\right) \\
\text { at }-1080 \mathrm{mV}\end{array}$ \\
\hline \multirow[t]{4}{*}{22} & $\begin{array}{l}\text { Air } \\
\text { saturation }\end{array}$ & 8.2 & -1040 & 1.0 \\
\hline & & $\begin{array}{l}7.7 \\
7.2\end{array}$ & $\begin{array}{l}-850 \\
-725\end{array}$ & $\begin{array}{l}2.3 \\
4.0\end{array}$ \\
\hline & 5.0 & $\begin{array}{l}8.2 \\
7.7 \\
7.2\end{array}$ & $\begin{array}{l}-1140 \\
-845 \\
-735\end{array}$ & $\begin{array}{l}0 \\
2.4 \\
2.4\end{array}$ \\
\hline & 3.0 & $\begin{array}{l}8.2 \\
7.7 \\
7.2\end{array}$ & $\begin{array}{l}-1170 \\
-820 \\
-715\end{array}$ & $\begin{array}{l}0 \\
1.3 \\
4.1\end{array}$ \\
\hline \multirow[t]{2}{*}{15} & 5.0 & $\begin{array}{l}8.2 \\
7.7 \\
7.2\end{array}$ & $\begin{array}{l}-805 \\
-750 \\
-700 \text { (Pitted) }\end{array}$ & $\begin{array}{c}3.3 \\
4.4 \\
(1.1)\end{array}$ \\
\hline & 3.0 & $\begin{array}{l}8.2 \\
7.7 \\
7.2\end{array}$ & $\begin{array}{l}-840 \\
-805 \\
-750\end{array}$ & $\begin{array}{l}0.8 \\
1.4 \\
2.7\end{array}$ \\
\hline 8.5 & 3.0 & 7.8 & -770 & $1.4^{-}$ \\
\hline \multirow[t]{2}{*}{4.0} & 7.2 & $\begin{array}{l}8.2 \\
7.7 \\
7.2\end{array}$ & $\begin{array}{l}-880 \\
-700 \text { (Pitted) } \\
-725\end{array}$ & $\begin{array}{c}1.2 \\
3.9\end{array}$ \\
\hline & 5.0 & $\begin{array}{l}8.2 \\
7.7 \\
7.2\end{array}$ & $\begin{array}{l}-825 \\
-775 \\
-750\end{array}$ & $\begin{array}{l}2.1 \\
1.4 \\
1.2\end{array}$ \\
\hline . & 3.0 & $\begin{array}{l}8.2 \\
7.7 \\
7.2\end{array}$ & $\begin{array}{l}-860 \\
-750 \\
-740\end{array}$ & $\begin{array}{l}1.3 \\
0.4 \\
0.6\end{array}$ \\
\hline , & 0.6 & $\begin{array}{l}8.2 \\
7.7 \\
7.2\end{array}$ & $\begin{array}{l}-840 \\
-770 \\
-750\end{array}$ & $\begin{array}{l}0.5 \\
0.8 \\
0.3\end{array}$ \\
\hline
\end{tabular}


temperature combinations not shown graphically. Each curve is characterized by its corrosion potential and by the current density (i) at a potential of $-1080 \mathrm{mV}$ SCE. The rationale for choosing $-1080 \mathrm{mV}$. is discussed later in this report. The trend within any set combination of DO and temperature is for the corrosion potential to become more noble and the current density at $-1080 \mathrm{mV}$ to become larger with decreasing $\mathrm{pH}$. At $4^{\circ} \mathrm{C}$ and $\mathrm{DO} \leq 5 \mathrm{ppm}$ the current densities become very small and the trend with decreasing $\mathrm{pH}$ is reversed.

\section{AlZoy 5052 in $3 \% \mathrm{NaCl}$}

In $3 \% \mathrm{NaCl}$ at room temperature and' air saturation, the effect of $\mathrm{pH}$ on cathodic polarization (Figure.22) is smaller than in natural seawater, but is still present at current densities up to about $1.5 \mu \mathrm{A} \mathrm{cm}{ }^{-2}$. At higher current densities there is.no significant difference between polarization curves at $\mathrm{pH} 7.2$ and 8.2. The vertical error bars represent the envelope of the data from at least five runs at each $\mathrm{pH}$, each using a freshly pickled electrode.

\section{Cathodic. Polarization of 99.99\% Aluminum}

When cathodic polarization data were repeated for $99.99 \%$ aluminum in seawater at room temperature, the results shown in Figures 23 and 24 were obtained. Corrosion potentials were more active as expected, and the effects of dissolved oxygen (Figure 23) and $\mathrm{pH}$ (Figure 24) were in the same direction as on alloy 5052, but smaller. The $\mathrm{pH}$ effect, in particular, disappears at current densities greater than about $2 \mu \mathrm{A} \mathrm{cm}{ }^{-2}$.

\section{DISĆUŚSION}

The objectives of this research were to determine what factors may have been responsible for the accelerated deep ocean corrosion rates of 5000 series aluminum alloys that have sometimes been observed and to assess what an increased corrosion rate might mean to an OTEC installation using alloy 5052. heat exchanger and condenser tubing. It would be well, at this time, to keep in mind that it is only the average pit depth: for all 5000 series alloys that has been shown ${ }^{19}$ to vary: according to Figure 1. As was pointed out in the Introduction, in-situ data for individual 5000 series alloys in the deep ocean are widely scattered and may or may not follow the trend shown by the average.

Our laboratory. data presented in Figures 3 through 24 are consistent with both the average trend and the individual scatter. Our data strongly support 


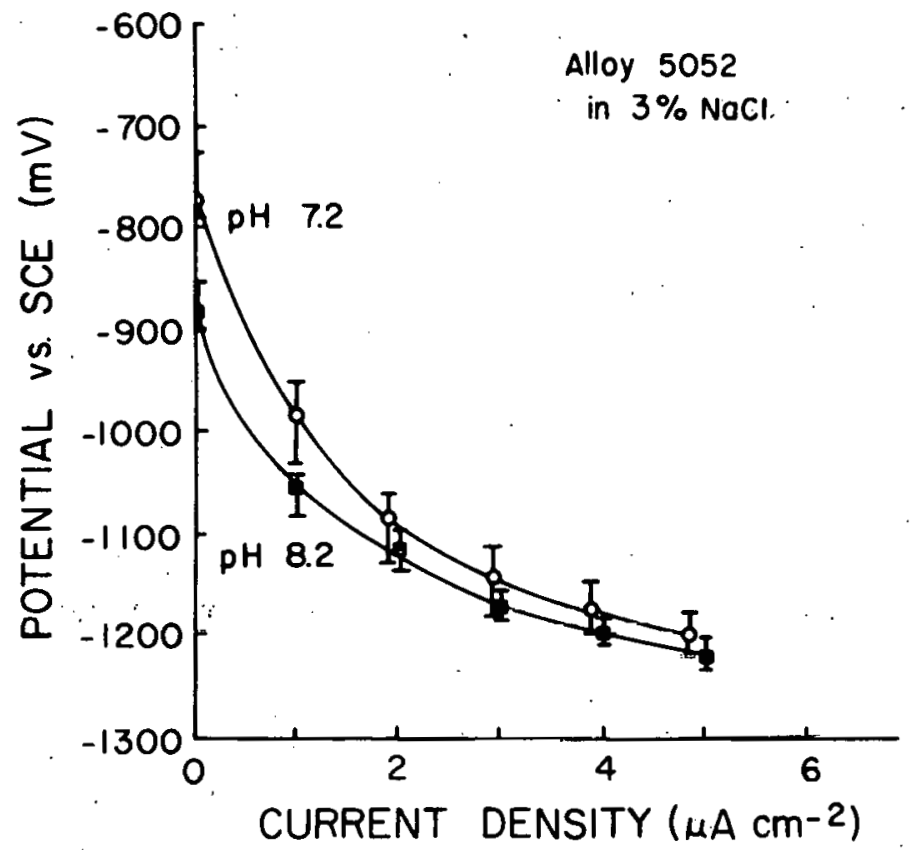

Figure 22. Cathodic Polarization of Alloy 5052 in Air-saturated $3 \% \mathrm{NaCl}$ at $23 \pm 2{ }^{\circ} \mathrm{C}$

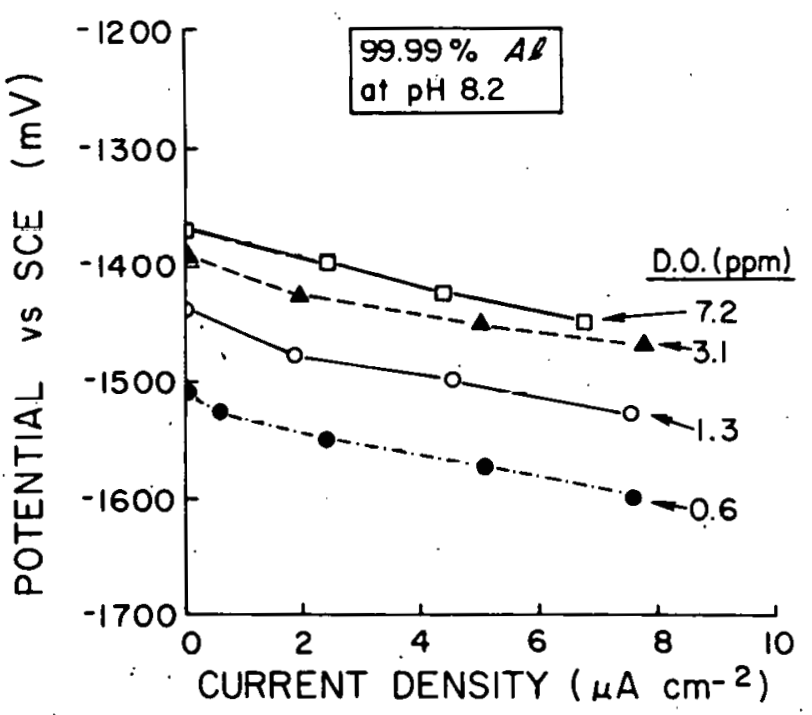

Figure 23. Effect of Do on Cathodic. Polarization of $99.99 \%$ Aluminum in Seawater at $\mathrm{pH} 8.2$

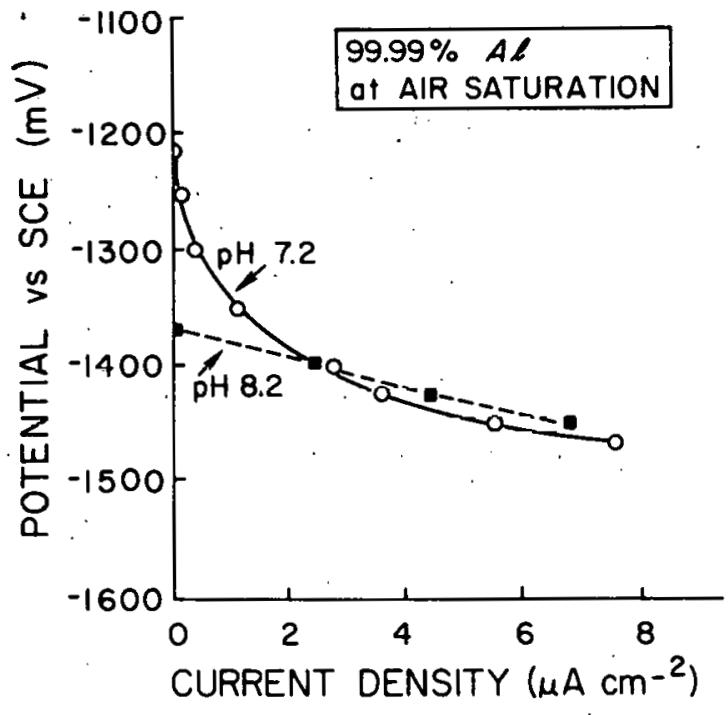

Figure 24. Influence of $\mathrm{pH}$ on Cathodic Polarization of $99.99 \%$ Aluminum in Air-saturated Seawater 
the possibility of increased deep ocean corrosion rates for alloy 5052, while at the same time, allowing us to better understand why a great deal of individual scatter has also been observed. It is significant to OTEC, however, that our data predict that if greater depth resolution were available in Figure 1, the maximum corrosion rate would not necessarily coincide with the depth of the dissolved oxygen minimum, but would be located at some lesser depth, at. intermediate values of oxygen, temperature and $\mathrm{pH}$. Let us now take a closer look at the data to see how these conclusions were reached. Although our data are consistent with increased corrosion rates in the deep. ocean, they are not consistent with the idea ${ }^{8,19}$ that 1 ow dissolved oxygen concentrations in the deep ocean are responsible. A decrease in dissolved oxygen, all other factors held constant, reduces rather than increases the rate of pit and crevice growth as measured by cathodic polarization (see Figures 10 and 11). In addition, the data on pit and crevice initiation indicate that a decrease in dissolved oxygen prolongs rather than decreases the induction time. This means that a decrease in dissolved oxygen with depth in the Pacific Ocean cannot be responsible for an increased corrosion rate.. On the other hand, a decrease in $\mathrm{pH}$ (again all other factors held constant) from the 8.2 characteristic of surface seawater, to 7.5 , typical of deep Pacific Ocean waters, both reduces the induction time for corrosion to start (Figure 8) and increases current density for a given potential at cathodic sites (i.e. decreases polarization, Figures 14 and 15). The cathodic current density controls and is proportional to the observed corrosion rate at anodic sites, 26 and this means higher pit and crevice growth rates at low $\mathrm{pH}$. The effect of a decrease in temperature, when varied independently, was to increase the probability of pit and crevice initiation by making the corrosion potential more noble (Figure 5), but to decrease the growth rate by making cathodic polarization more rapid.

More important to OTEC than these individual variations is what happens when $\mathrm{pH}$, oxygen and temperature are varied together as they do in the real ocean. The necessary information is contained in the cathodic polarization curves of Figures 17 through 21; however, in order to relate these data to an OTEC plant, we must first have a calibration point. That 1 , we must determine at what value of potential the curves should be compared. Once this is known, current densities can be read directly from the appropriate curves and 
converted to predicted average corrosion rates using Faraday's law, which relates weight of metal corroded per unit time to current density.

The needed calibration point is most easily deduced from weight-loss data. Using Faraday's law, one can calculate the average current density necessary to account for a given weight loss over a given period of time. From Godard's weight-loss data ${ }^{9}$ for alloy 5052 in Halifax, Nova Scotia surface water and Reinhart's datal9 in deep Pacific waters, it was calculated that the appropriate average current densities are approximately 0.3 to $1.0 \mu \mathrm{A} \mathrm{cm} \mathrm{cm}^{-2}$ in surface water and 1.0 to $2.0 \mu \mathrm{A} \mathrm{cm}^{-2}$ in deep Pacific water. The higher numbers in each of these ranges are from short-term (one year or less) data and the lower numbers from longer term data, probably reflecting a decrease in corrosion rate with time as corrosion product films build up. ${ }^{9}$

Returning now to Figure 21, where $\mathrm{pH}$, dissolved oxygen and temperature are varled together, the potential corresponding to a current density of $1 \mu \mathrm{A} \mathrm{cm}{ }^{-2}$ on the curve for surface-water conditions ( $\mathrm{pH} 8.2$, Do $7.2 \mathrm{ppm}$ ) is about $-1080 \mathrm{mV} \mathrm{SCE}$. Presumably, the active pits have polarized the metal to this potential after they initiated at the critical pitting potential. Assume now that regardless of the initial environmental conditions, an active pit or crevice will always polarize the electrode to about this same $-1080 \mathrm{mV}$. The intersections of each curve with a horizontal line at this potential can then be used to predict the cathodic current density under conditions corresponding to the curve of interest. The approximate Pacific Ocean depths corresponding to the curves in Figure 21 were shown in Table II. The intersection of the horizontal 1,ine at $-1080 \mathrm{mV}$ with the curve corresponding to the DO-pH minimum is at $0.3 \mu \mathrm{A} \mathrm{cm}{ }^{-2}$. This predicts that pit and crevice growth rates will be slower here than at the surface. This does not: necessarily mean lower overall corrosion rates than at the surface, however, because the corrosion potential at conditions corresponding to the DO- $\mathrm{pH}$ minimum is only about $50 \mathrm{mV}$ active to the critical pitting potential. Such a noble corrosion potential may encourage more rapid pit initiation than in surface water where the corrosion potential is $300 \mathrm{mV}$ more active. It is - difficult to say in any given situation whether initiation or growth will be more important, and this uncertainty could account for some of the scatter that has been observed in the data from field tests. 19 
The two curves in Figure 21 that correspond to intermediate values of $\mathrm{pH}$, DO and temperature both show current densities at $-1080 \mathrm{mV}$ higher than those for surface-water conditions. In addition, these two curves also start from noble corrosion potentials. Both initiation and growth will be accelerated under these conditions, therefore, and overall corrosion rates are expected to be larger than at the surface. This is the basis on which it was concluded that our data are consistent with increased corrosion rates in the deep ocean, but that the maximum rate should occur at a lesser depth than that of the dissolved oxygen minimum.

In general, the most corrosive conditions encountered in these experiments were ones combining low temperature and low pH with high dissolved oxygen. These conditions encourage both noble corrosion potentials, which can lead to rapid initiation, and increased cathodic current densities, which lead to higher growth rates. It is fortunate for OTEC that this most corrosive set of conditions is almost never found together in the real environment. Low dissolved oxygen and low $\mathrm{pH}$ are closely coupled in the ocean. The dissolved oxygen minimum is caused by biological decay of descending organic matter. This process not only consumes oxygen but also produces $\mathrm{CO}_{2}$, which simultaneously keeps the $\mathrm{pH}$ low. ${ }^{30}$ In the Pacific Ocean, low temperature and low $\mathrm{pH}$ occur together but the oxygen is a.lso low, which reduces the corrosivity. In the deep Atlantic Ocean, high oxygen can be found together with low temperature but now the $\mathrm{pH}$, which is coupled to dissolved oxygen, will be high, 30 again reducing the corrosivity. Since the most corrosive combination of low $\mathrm{pH}$ and high Do does not occur naturally, Figure 21 predicts that the most corrosive natural conditions will be those in the midrange of all three variables. Here, the temperature and $\mathrm{pH}$ are both low enough to make the corrosion potential noble, but the Do is still high enough to permit reasonably high growth rates. In the Pacific Ocean (see Figure 2) these conditions are most usually found at depths of 150 to 400 meters, while in the Atlantic they may be found at greater depths due to the higher overall levels of $\mathrm{D0} .{ }^{30}$ The data strongly suggest that OTEC should avold locating efther warm or cold water intakes at such depths.

To summarize our discussions so far, then, the general effects of $\mathrm{pH}$, DO and temperature are as follows. Low $\mathrm{pH}$ encourages the initiation of both pitting and crevice corrosion and increases the growth rate. Low dissolved oxygen does the opposite. It both suppresses initiation and decreases the 
growth rate. The effect of low temperature is mixed. It increases the tendency for initiation by shifting the corrosion potential in the noble direction but decreases the growth rate. The most corrosive naturally occurring combination of these variables is in the midrange of all three. Thus, an obvious recommendation is that (a) profiles of $\mathrm{DO}, \mathrm{pH}$ and temperature be obtained at all potential OTEC sites, and (b) cathodic polarization curves at all appropriate sets of conditions be run before the design depths of warm and cold water intakes are fixed for any future OTEC plant.

Recent results reported by Munier and $\mathrm{Craig}^{31}$ are encouraging in that they encountered no pitting or crevice attack on heat exchanger tubing of either alloy 5052 or the less resistant $6061-T 6$ in the St. Frnix QTEC currusion experiments over a 72-day test perind. Munier and Craig aro quick to point out, however, that their results were obtained under ideal OTEC conditions of continuous flow, 27 to $29^{\circ} \mathrm{C}, 4$ to $5 \mathrm{\mu g}$-atm/1iter of dissolved oxygen and $\mathrm{pH} 8.0$ to 8.2 . Our results confirm that these are, indeed, the least corrosive of naturally occurring seawater conditions. The benefit to OTEC of maintaining a continuous flow is also demonstrated by their data in that a number of their initial corrosion potentials were more noble than the critical pitting potential at their salinity (about -0.725 . volts $\mathrm{Ag}-\mathrm{AgCl}$ ), and yet they experienced no pitting. This should be attributed to the inhibitive effect on pit initiation of a continuous flow. Our results indicate that pitting would have occurred had their noble potentials been encountered under quiescent conditions. This indicates the importance to OTEC of maintaining constant velocity conditions.in the heat exchanger tubing. Times when the unit is shut down for maintenance will be particularly critical-especially the initial installation period before protective corrosion products films have a chance to build up. If aluminum tubing is eventually chosen for OTEC, our data indicate that operational procedures should be developed that will prevent zero velocity conditions in the tubing from persisting for more than about 10 minutes during initial startup or 10 hours during subsequent shut-down periods. Some provision for complete drainage of the aluminum tubing should be provided in the design to accommodate longer shut-down periods.

Although some pit initiation is probably inevitable, short initiation times may not be of critical concern to OTEC because the rate of penetration of aluminum alloys by pitting in aqueous media are usually found to decrease with time. Godard et al. ${ }^{9}$ report that the maximum pit depth of aluminum in 
fresh waters, and frequently also in seawater, varies with the cube root of time. This cube root relationship can be derived by assuming that a mature pit is spherical in shape and that its volume; 'or the weight loss of the specimen, increases linearly with time, $t$ (i.e. $V \propto t$ ). Since the volume varies with the radius, $r$, cubed, the pit depth, $d$ is proportional to $\mathrm{V}^{1 / 3}$; and it follows that $d=2 r=\mathrm{Kt}^{1 / 3}$, where $\mathrm{K}$ is a proportionality constant dependent on the specific material and environment.

Let us now see how the cube root law can be combined with our cathodic polarization data to develop a procedure for predicting the rate of penetration of OTEC tubing by pitting corrosion. If one takes the surface seawater weight-loss data published by Godard ${ }^{9}$ for alloy 5052 at Halifax, Nova Scotia, and plots it against exposure time, a straight line is obtained as seen in Figure 25. Since the weight loss is linear with time, the cube root relationship holds, and one is justified in applying this relationship to Godard's data in order to calculate the pit depth (or tube wall thickness required) as a function of desired service lifetime. If the weight loss falls off with time rather than remaining linear, then the following procedure will overestimate the wall thickness required.

First notice that in Figure 25, a straight line drawn through Godard's data does not pass through the origin. Godard cleaned his coupons with $50 \%$ phosphoric acid before measuring weight loss, and it is speculated that this resulted in each measurement being too high by a constant factor. Therefore, the curve has been translated down to pass through the origin, and the weight-loss data for the ensuing calculations will be taken from the dotted line. Assuming that ail pits initiate simultaneously upon immersion, are the same size and are spherical in shape, the pit depths can be calculated as follows. The weight loss from Figure 25, density of aluminum, and volume of the pit are related by the expression,

$$
\frac{\text { weight loss }}{\text { density }}=\text { volume }=\frac{4}{3} \pi r^{3}=\frac{4}{3} \pi\left(\frac{d}{2}\right)^{3} \text {, }
$$

where $r$ is the radius of the spherical pit, and $d$ is the pit depth. Solving for $d$ and taking the density of aluminum to be about $2.7 \mathrm{~g} / \mathrm{cc}$, pit depths can be calculated as a function of time and the number of pits per unit area of surface (the pit density). The results appear in Table IV. Lifetimes are shown from 1 to 20 years, and pit densities are expressed both as a hypothetical total number of pits on Godard's $2-\mathrm{ft}^{2}$ coupons and as the number of pits 
Wall Thickness of Tubing Required for Various Lifetimes and P1t Densities

\begin{tabular}{|c|c|c|c|c|c|c|c|}
\hline \multirow{2}{*}{$\begin{array}{l}\text { No. of Pits } \\
\text { on } 2-f t^{2} \\
\text { Coupon }\end{array}$} & \multirow{2}{*}{$\begin{array}{l}\text { No. of } \\
\text { Pits } \\
\text { per } \mathrm{cm}^{2}\end{array}$} & \multicolumn{6}{|c|}{$\begin{array}{l}\text { Pit Depth or Wall } \\
\text { Thickness (mm) Required, } \\
\text { at Indicated Lifetime }\end{array}$} \\
\hline & & $1 \mathrm{yr}$ & $2 \mathrm{yr}$ & 5 y.r & $10 \mathrm{yr}$ & $15 \mathrm{yr}$ & $20 \mathrm{yr}$ \\
\hline 1 & $5.3 \times 10^{-4}$ & 9.63 & 12.12 & 16.50 & 20.73 & 23.70 & 26.12 \\
\hline 10 & $5.3 \times 10^{-3}$ & 4.47 & 5.63 & 7.64 & 9.62 & 11.02 & 12.12 \\
\hline $10^{2}$ & $5.3 \times 10^{-2}$ & 2.08 & 2.61 & 3.55 & 4.45 & 5.11 & 5.63 \\
\hline $10^{3}$ & $5.3 \times 10^{-1}$ & 0.96 & 1.21 & 1.65 & 2.06 & 2.37 & 2.61 \\
\hline $10^{4}$ & 5.3 & 0.45 & 0.56 & 0.76 & 0.96 & 1.10 & 1.21 \\
\hline $10^{5}$ & $5.3 \times 10^{1}$ & 0.21 & 0.26 & 0.35 & 0.45 & 0.51 & 0.56 \\
\hline $10^{6}$ & $5.3 \times 10^{2}$ & 0.10 & 0.12 & 0.16 & 0.21 & 0.24 & 0.26 \\
\hline
\end{tabular}

* Based on data of Godard (1967) for Halifax surface water. Assumes all pits initiate "pon immersion, are the same size aind ale splierled in shape. For hemispherical pits, mult1ply all depths by 0.4 , 


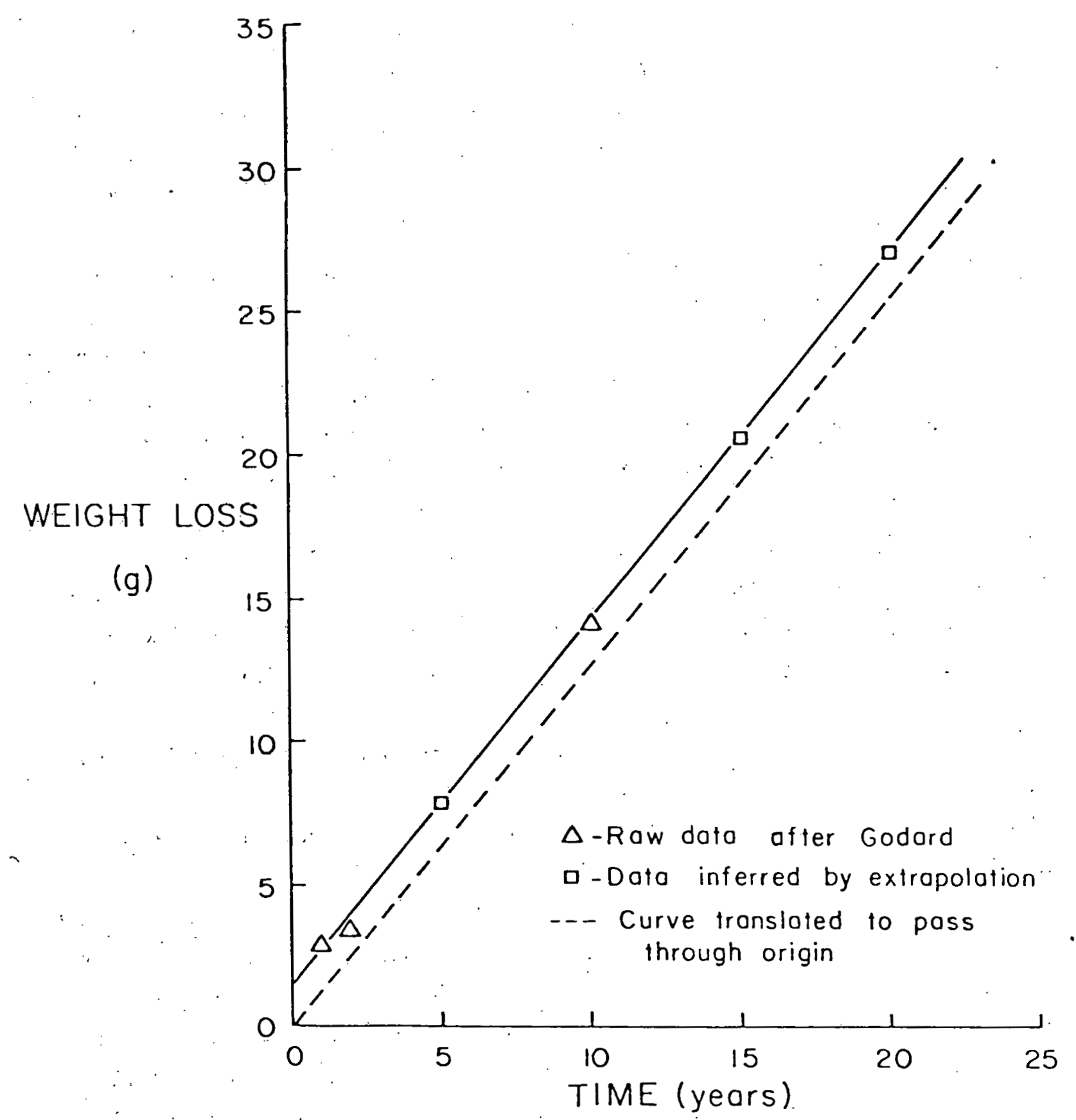

Figure 25. Corrosion Weight-loss Data for Alloy 5052 in Halifax Seawater (from Godard) 
per square centimeter of surface. In the first row of the table, all the weight loss from Figure 25 is considered to be the result of one single pit. In each succeeding row, the number of pits over which the weight loss is distributed is increased by an order of magnitude. It is realized that Godard's data are not strictly applicable to OTEC conditions because his panels were fouled, whereas OTEC heat exchanger surfaces will be kept clean. Godard's data have been used here as an example of what can be done, and any new sets of data that were done under OTEC conditions could be treated in the same manner.

The general methodology for prediction will be to use data such as those in Table IV from a well known set of conditions together with our cathodic polarization data to predict the relative rate of penetration under a new set of conditions. To illustrate how this might be done, suppose it is desired to keep the heat exchanger or condenser tube wall thickness no larger than $1 \mathrm{~mm}$. For a pit density of $0.5 / \mathrm{cm}^{2}$, the lifetime would be one year. If however, one could induce $5.3 \mathrm{pits} / \mathrm{cm}^{2}$, a lifetine of 10 years could be obtained. That such pit densities are realistic is implied by Godard's weight-loss and maximum pit depth data for alloy 5052 in Halifax seawater. A two-year exposure resulted in a maximum pit depth of 20 mils (about $0.5 \mathrm{~mm}$ ) and a weight loss of $2.5 \mathrm{~g}$ (Figure 25). Table IV indicates that for a uniform pit depth of $0.5 \mathrm{~mm}$ and a two-year exposure, a pit density of $5.3 \mathrm{pits} / \mathrm{cm}^{2}$ would be required to account for the weight loss reported. This type of data comparison is valid only if the pits are approximately spherical in shape. If the pits are broad and shallow, lower numbers of them would be needed.

Use of the type of data found in Table IV also allows one to take into account other factors sirh as nonuniform distritullon of pit depths. If, as may be the case in actual service, the pits are not all the same depth, then it is necessary to know how much deeper than average the deepest pit is. This factor could be used as a multiplier for the depths shown in Table IV. In a similar manner, the intersections of a horizontal line at $-1080 \mathrm{mV}$ with the polarization curves in Figure 21 could be used as multiplying factors for Table IV to account for the effects of $\mathrm{pH}$, DO and temperature in the deep ocean. Again, if this method were to actualiy be used for penetrationrate predictions, Godard's data would have to be replaced by equivalent data run under actual or simulated OTEC conditions, and our surface seawater curve 
from Figure 21 would have to be redone under those same conditions. The present data, however, serve well enough to 1llustrate the method.

Two other variables will need to be included before predictions of actual tubing lifetimes can be attempted. These are the velocity of fluid flow and the pit density. Velocity is expected, like temperature, to have two competing effects. An increase in velocity should suppress pit initiation, but once a pit gets started, the increase in transport of oxygen to cathodic sites on the surface may accelerate pit growth. This possibility may be particularly serious under deep ocean conditions where increased transport of dissolved oxygen by the velocity in the OTEC tubing may artificially create the most corrosive combination of low $\mathrm{pH}$, low temperature and high oxygen.

Pit density data for 5000 series alloys in the deep Pacific Ocean reported by Reinhart ${ }^{19}$ are scattered over one and one-half orders of magnitude. Figure 26 shows these data plotted against $\mathrm{pH}$. The scatter looks about the same when the data are plotted directly as a function of depth. Godard $^{9}$ does not give the pit density as such in his data on corrosion of 5000 series alloys in surface seawaters but it can be calcualted approximately from the weight loss and average pit depth, which are reported. The results are no more consistent than those in Figure 26. Since the pit density data reported in the literature are so varfable, it will probably be necessary for us to learn how to control it. An experimental program for doing this and for determining the effect of velocity on the cathodic polarization data has been proposed to OTEC by the present author, but has not yet been funded.

One additional factor remains to be discussed, and this is the concentration of heavy metal ions--especially cupric ion. Since initiation times for pitting of alloy 5052 in seawater without $\mathrm{Cu}^{++}$additions are usually less than two weeks, shorter induction times in the presence of increased $\mathrm{Cu}^{++}$are not of engineering significance. An increase in cupric ion concentration could, however, increase pit growth rates of alloy 5052 by creating a noble and more efficient cathodic surface for the reduction of dissolved oxygen. In the case of $99.99 \%$ aluminum, which is resistant to pitting in clean seawater, an increase in $\mathrm{Cu}^{++}$could lead to both reduced induction times and to increased growth rates. This could be important if 99.99\% aluminum or a similar alloy is used for cladding. 


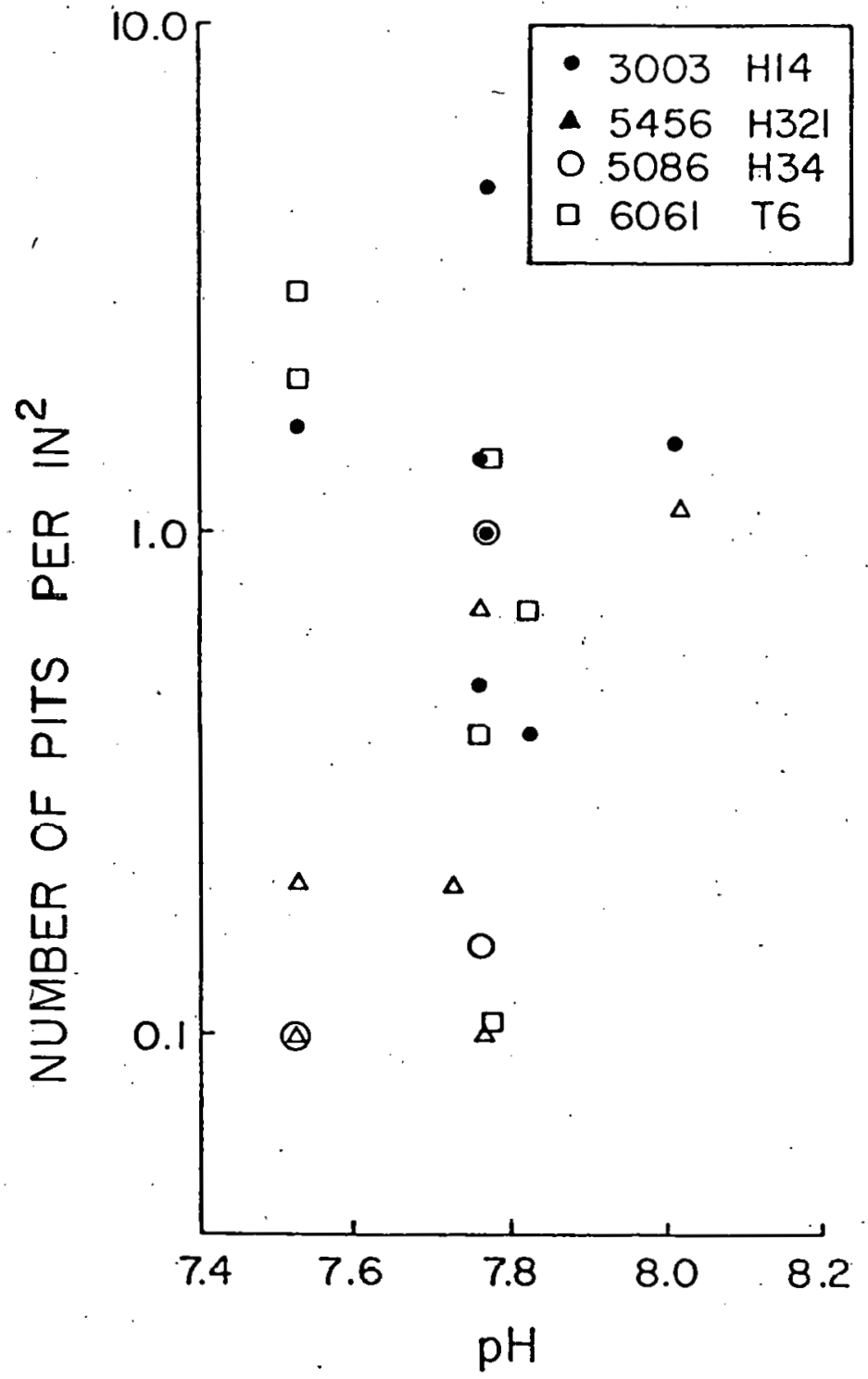

F1gure 26. Pit-density Data Reported by Reinhart ${ }^{19}$ for Aluminum Alloys at the Pacific Ocean Test Site Plotted as a Function of Seawater $\mathrm{pH}$ 
Since it has been proposed to use 90-10 copper-nickel screening for the warm water intake, it is important that two things be established: (a) The threshold limit of copper below which pit and crevice growth rates of alloy 5052 and 99.99\% aluminum will not be increased, and the pit initiation time for pure aluminum will not be decreased; and (b) The level of copper in the water passing through the evaporator resulting from use of a coppernickel intake screen. If the threshold value in (a) is lower than the level of copper in (b) and if copper-nickel screening must still be used, then it will be necessary to measure a multiplying factor to use with Table IV in determining the proper tube wall thickness to withstand the accelerated growth rates. This can be done using present potentiostatic techniques. In light of the above discussion, it is suggested that there are two alternative approaches to heat exchanger corrosion control for the OTEC project. These are (a) avoiding perforation of the tubing by inducing as many pits as possible and selecting the proper tube wall thickness as per the methodology outlined above, or (b) attempting to avoid pitting altogether by cladding and not allowing zero velocity conditions to develop. Based on our data, the chances of avoiding pitting altogether over a 10 or 20-year lifetime would seem rather slim. If this is true, then the pertinent engineering questions become (a) how thick does the tube wall need to be to withstand the most severe conditions at a given oceanic site as a function of pit density and desired lifetime, and (b) what can be done to induce a high density of pits or to control the pit density-especially on a structure the size of OTEC, and (c) what will be the effect of intermittent mechanical cleaning on pit initiation and propagation rates? Three general approaches that might be used to achieve a high and controllable pit density are (a) inducing pits by a timed pulse of applied anodic current, (b) application of a porous aluminum surface coating by electrolytic methods, spraying or powder metal technology, or (c) changing the conductivity or defect structure of the passive film by alloying. The solutions to these questions, put in context with economic considerations will determine whether or not alloy 5052 can successfully be used for OTEC heat exchanger tubing, and if so, whether the bare alloy can be used or a clad construction will be necessary. 


\section{CONCLUSIONS}

1. The data presented are consistent with the increased corrosion rates reported in the literature for 5000 series aluminum alloys in the Pacific Ocean.

2. These increased rates are caused by a combination of decreasing $\mathrm{pH}$ and temperature with depth rather than by a lower dissolved oxygen concentration.

3. Decreasing the $\mathrm{pH}$ of seawater from 8.2 to 7.2 increases the corrosion rate of aluminum alloy 5052 by both encouraging pit initiation and increasing pit growth rates. Decreasing the dissolved oxygen concentration from air saturation to $0.6 \mathrm{ppm}$ has the opposite but smaller effect. Limited data indicate that $99.99 \%$ aluminum behaves similarly but is affected to a lesser degree.

4. Polarization data predict that the maximum corrosion rate for aluminum alloy 5052 in the deep ocean may be greater than that reported by Reinhart and will occur at depths having intermediate values of $\mathrm{DO}, \mathrm{pH}$, and temperature (150 to 200 meters in the Northwestern Pacific).

5. The induction time for the initiation of pitting and crevice corrosion of alloy 5052 in clean seawater can be relatively short--on the order of days. For $99.99 \%$ aluminum, the induction times are longer, and there are indications that $99.99 \%$ aluminum may not corrode at all in the absence of heavy metals and at pH more basic than 7.6.

6. Due to the possibility of short induction times for corrosion initiation, in alloy 5052, it is suggested that OTEC consider the following alternatives: (a) avoiding pitting of the base metal altogether by cladding with $99.99 \%$ aluminum or an alloy that behaves similarly and designing to avoid zero velocity flow conditions, or (b) controlling perforation of unclad tubing by inducing as high a pit density as possible and selecting the proper wall thickness according to the procedure outlined in this report.

\section{RECOMMENDATIONS}

1. Measure profiles and seasonal variabilities of $\mathrm{DO}, \mathrm{pH}$ and temperature at all potential OTEC sites.

2. Obtain cathodic polarization data under all appropriate sets of conditions measured above before the cold and warm water intake design depths are fixed. 
3. Using the polarization data above, avoid locating intakes at depths having the most corrosive sets of conditions. In most cases, it should be possible to locate. the warm water intake above and the cold water intake below the most corrosive depth.

4. Fund the experiments already proposed on the effects of pit density and velocity so the predictive methodology can be ready to use when needed for design and location of large OTEC plants.

5." Fund experiments to determine the effect of intermittent mechanical cleaning on pitting.

6. Avoid copper-nickel components upstream of aluminum heat exchanger tubing if at all possible. If not possible, fund the experiments recommended in this report to determine whether increased corrosion will be a design consideration.

7. Design heat. exchangers to avoid zero velocity flow conditions, and for complete drainage of the tubing in the event of shut-down periods longer than about half a day.

8. Carefully examine all proposed cleaning techniques, and when aluminum tubing is used, reject any that could lead to even a temporary combination of low $\mathrm{pH}$ and high $\mathrm{DO}$ on the seawater side of the tube.

\section{ACKNOWLEDGMENTS}

Support of this work under ERDA/DOE Contract No. EY-76-S-02-2957 (formerly E(11-1)-2957) is gratefully acknowledged. This work was monitored by Dr. L. Perrigo of the Battelle Pacific Northwest Laboratory, whose guidance is greatly appreciated. In addition, thanks are due D. Ferrick, R. Rotter and $\mathrm{K}$. Lucas for help with the experimental work and to $\mathrm{W}$. Boyd, F. L. LaQue and H: H. Uhlig for many helpful discussions. 


\section{REFERENCES}

1. S. C. Dexter. On the Localized Corrosion of Aluminum Alloys for OTEC Heat Exchangers. In Proc. OTEC Biofouling and Corrosion Symposium. R. H. Gray, editor. Seattle, p. 223, October (1977).

2. S. C. Dexter. Handbook of Oceanographic Engineering Materials, WileyInterscience, New York, 1979:

3. R. A. Bonewitz. Concurrent Studies of Enhanced Heat Transfer and Materials for Ocean Thermal Exchangers. Final Report ERDA Contract No. E(11-1) -2641, 69 pP (1976).

4. W. H. Ailor, Jr. Five-year Corrosion of Aluminum Alloys at Several Marine Sites. British Corrosion Journal, 1 , 327-343 (1966).

5. W. H. Ailur, Jr. Ten Year Seawater Tests on Aluminum. In: Corrosion in Natural Environments. ASTM STP 558, American Society for Testing and Mater1als, p. 117-134 (1974).

6. W. H. Ailor, Jr. and R. I. Lindberg. Corrosion Resistance of Aluminum Alloy 5083 in Marine Environments. J. American Soc. of Naval Eng., 73, No. 3 (1961).

7. W. H. Ailor, Jr. and F. M. Reinhart. Three-year Tidewater Corrosion of Aluminum Alloys. Naval Engineers Journal, June (1964).

8. F. W. Fink and W. K. Boyd. The Corrosion of Metals in Marine Environments. Bayer and Co., Inc., Columbus, Ohio (also DMIC Report 245), pp. $57-70$ (1970).

9. H. P. Godard, W. B. Jepson. M. R. Bothwell and R. T.. Kane. The Corrosion of Light Metals. John Wiley and Sons; Inc. ( $\overline{1967}$ ).

10. H. P. Godard and F. F. Booth. Corrosion Behavior of Aluminum Alloys in Seawater. In: Congress International de la Corrosion Marine et des Salissures, Cannes, France, PP. 37-52 (1964).

11. C. K. Southwell et al. Corrosion of Metals in Tropical Environments. Materials Protection, 15 (1976).

12. F. M. Reinhart. Corrosion of Materials in Surface Seawater after 6 Months Exposure. Naval Civil Engineering Laboratory, Port Hueneme, California, Technical Note N-1023 (1969):

13. R. E. Groover, T. J. Lennox, Jr,, and M. H. Peterson. Cathodic Protection of Nineteen Aluminum Alloys Exposed to Seawater Corrosion. Materials Protection and Performance, $\underline{8}$, No. 11 (1969). 
14. R. E. Groover, T. J. Lennox, Jr, and M. H. Peterson. Characterization of the Corrosion Behavior and Response to Cathodic Protection of Nineteen Aluminum Alloys in Seawater. Naval Research Laboratory, Washington, D.C.; NRL Memorandum Report No. 1961, AD685588, 23 Pp. (1969).

15. J. S. Snodgrass. Progress in the Utilization of Aluminum in Desalting. Paper No. 90 presented at the NACE-sponsored meeting CORROSION/72, 17 pp (1972).

16. P. F. George, J.A. Manning, Jr., and C. F. Schrleber. Desalination Materials Manual. Dow Chemlcal Co., for the Office of Water Research and Technology, Nat1onal Technical Information Service, PB-252 043 (1975).

17. W. H. Ailor, Jr. Evaluation of Aluminum Panels Exposed in the Pacific Ocean at 2340 Feet for Six Months. Metallurgica, March (1967).

18. W. H. Ailor, Jr. Evaluation of Aluminum after One Year Deep Sea Exposure. Journal of Hydronautics, 2, No. 1, pp. 26-33 (1968).

19. F. M. Reinhart. Corrosion of Materials in Hydrospace, Part V. Aluminum Alloys. U.S. Naval Civil Engineering Laboratory, Port Hueneme, California, Technical Note N-1008 (1969).

20. W. S. Broecker. Chemical Oceanography. Harcourt, Brace, Jovanovich, Inc., 6 pp (1974):

21. F. L. La Que. Marine Corrosion. John Wiley and Sons, Inc., 209 pp (1975).

22. H. L. Craig, Jr. Kinetic Studies of Aluminum Pitting Reactions; In: Localized Corrosion, R. W. Staehl, editor, NACE, Houston, Texäs, PP. 600-607.(1974).

23. F. C. Porter and S. E. Hadden. Corrosion of Aluminum in Supply Waters. J. Appl. Chem., 3, 385 (1953).

24. W. A. Bell and H. S. Campbel1. Aluminum in Fresh Waters. British Corrosion Journal, 1,72 (1965):

25. H. Bohni and H. H. Uhlig. Environmental Factors Affecting the Critical Pitting Potential of Aluminum. J. Electrochem. Soc., 116, 906 (1969).

26. H. H. Uhlig. Corrosion and Corrosion Control, Second Edition. John Wiley and Sons, Inc., 419 pp (1971). 
27. B. E. Wilde: On the Pitting and Protection Potentials: Their Use and. Misuses for Predicting Localized Corrosion Resistance of Stainless Alloys in Halide Media. In: Locallzed Corrosion. R. W. Staehle, editor, NACE, Houston, Texas, PP. 342-352.(1974).

28. H. Leckie and H. Uhlig. J. Electrochem. Soc., 113, 1262 pp (1966).

29. Handbook on Corrosion Testing and Evaluation. W. H. Ailor, Jr., editor. John Wiley and Sons, Inc., 171 pp (1971).

30. S. C. Dexter and C. H. Culberson. Global Varlability of Natural Seawater. Presented at CORROSION/79, NACE, Atlanta, March (1979), and Materials Performance Journal, in press (1980).

31. R.S.C. Munier and H. L. Craig. OTEC Biofouling and Corrosion Experiment St. Croix, U.S. Virgin Islands, Part II Corrosion Studies, OTEC Report PNL-2739, February (1978), 
Interna1:

P. H. Benson

J. J. Roberts

J. B. Darby, Jr.

N. F. Sather

J. D. Ditmars

A. Thomas

J. E. Draley (10)

ANL Contract File

B. R. T. Frost

ANL Libraries (5)

A. P. Gavin

TIS Files (6)

A. B. Krisciunas

External:

DOE-TIC, for distribution per UC-64 (42.3)

Manager, Chicago Operations and Regional office, DOE

Chief, Office of Patent Counsel, DOE-CORO

President, Argonne Universities Association

$\mathrm{J}$. Hilbert Anderson, Sea Solar Power, Inc.

M. Kent Anderson, Trane Air Conditioning

Takaaki Anzai, Florida Institute of Technology

W. H. Avery, Applied Physics Laboratory, Johns Hopkins University.

E. Barsness, Westinghouse Electric Corporation, Lester, PA

James 0. Bates, Energy Technology Engineering. Center

Kenneth J. Bell, Oklahoma State University

Robert A. Bonewitz, Aluminum Company of America

R. Cohen, US-DOE, Div. of Central Solar Technology

William A. Corpe, Columbia University

R. S. Dalrymple, Reynolds Metals Company, Richmond, VA

G. J. Danek, Annapolis, Maryland

James Denton, TRW Systems and Energy, Redondo Beach, CA

John DePalma, U, S. Naval Oceanographic Office

Stephen Dexter, University of Delaware (2)

John G. Fetkovich, Carnegie-Mellon University

Harry Foust, Trane Air Conditioning

Malcom D. Fraser, Intertechnology Corporation

John Gertz, Westinghouse. Electric Corporation, Lester, PA

Sigmund Gronich, US-DOE, Div. of Central Solar Technology

P. H. Hadley, Jr., Gibbs \& Cox, Inc.

L. W. Hallanger, Research Corporation, University of Hawail

William Hartt, Florida Atlantic University

William E. Heronemus, University of Massachusetts

F. K. Hill, Applied Physics Laboratory, Johns Hopkins University

Jules Hirshman, NYIT Research Center, Dania, FL

J. F. Jenkins, Civil Engineering Laboratory

E. H. Kinelski, US-DOE, Div. of Central Solar Technology

Robert E. Lacey, Southern Research Institute

F. L. LaQue, Verona, New Jersey

Abrahim Lavi, Carnegie-Mellon Universtty

T. S. Lee, International Nickel Company, Wrightsville Beach, NC

Murray Leitner, Lockheed Missiles and Space Co., Inc., Sunnyvale, CA

Lloyd Lewis, US-DOE, Div. of Central Solar Technology

Brenda Little, NORDA

D. Lott, Naval Coastal Systems Center 
Richard N. Lyon, Oak Ridge National Laboratory

Frank Mathews, Colorado School of Mines

John W. Michel, Oak Ridge National Laboratory

Ralph Mitchell, Harvard University

Robert L. Molinar1, NOAA/AMOL

R.S.C. Munier, Tracor Marine, Port Everglades, FL

John Nicol, Arthur D. Little, Inc.

Merle Olmsted, General Electric Company, Schenectady, NY

T. B. O'Neill, Civil Engineering Laboratory

Steven Pohlman, Solar Energy Research Institute

David Price, U. S. National Oceanic \& Atmospheric Administration

W. W. Pritsky, Aluminum Association

J. F. Rynewicz, Lockheed Missiles and Space Co., Inc., Sunnyvale, CA.

Donald Sasscer, University of Puerto Rico

C. F. Schrieber, Dow Chemical Company, Freeport, TX

H. H. Sephton, University of California at Berkeley

B. Shelpuk, Solar Energy Resparsh Inetitutc

William Sheppard, NOAA Data Buoy office

J. E. Snyder, TRW Systems and Energy, Redondo Beach, CA

Frank Spiehler, NOAA Data Buoy office

T. J. Summerson, Kaiser Aluminum and Chemical Corp., Pleasanton, CA

R. B. Teel, Chatham, New Jersey

D. L. Thomas, Charles T. Main, Inc.

Fred Vukovich, Research Triangle Institute

J. Paul Walsh, Value Engineering Company

E. T. Wanderer, Aluminum Company of America

Ralph L. Webb, Pennsylvania State University

Pat Wilde, University of California at Berkeley

Ralph Williams, PRC Energy Analysis Co.

David C. White, Florida State University

Hank White, Natural Energy Laboratory of Hawaii

Clarence Zener, Carnegie-Mellon University 